\title{
AVALIAÇÃO DA UNIFORMIDADE DE EMISSÃO E DA UNIFORMIDADE ESTATÍSTICA EM IRRIGAÇÃO LOCALIZADA
}

\author{
GILBERTO MANILLI FAVETTA
}

Engenheiro Agrónomo

Orientador: Prof. Dr. TARLEI ARRIEL BOTREL

Dissertação apresentada a Escola Superior de Agricultura "Luiz de Queiroz", da Universidade de São Paulo, para obtenção do título de Mestre em Agronomia, Area de Concentração: Irrigação e Drenagem

P I R A C I C A B A

Estado de São Paulo - Brasil

Abril - 1993 
Ficha catalografica preparada pela Seça de Livros da Divisán de Biblioteca e Documentasáa - PCLQ/USF

Favetta, Gilberto Manilli

F273g Avaliagro da uniformidade de emissào e da uniformidade estatistica em irrigaçao localizada. Firaci caba, 1993.

s.p.

Diss. (Mestre) - ESALQ

Eibliografia.

\&.' Irrigaça localizada Z. Vazao - Simulaça automatizada I. Escola Superior de Agricultura Luiz de Queiroz, Piracicaba 


\section{AVALIAÇÃO DA UNIFORMIDADE DE EMISSÃO E DA UNIFORMIDADE ESTATÍSTICA EM IRRIGAÇÃO LOCALIZADA}

GILBERTO MANILLI FAVETTA

Aprovado em: 04.06 .93

Comissão julgadora:

Prof. Dr. Tarlei Arriel Botrel ESALQNUSP

Prof. Dr. Decio Barbin ESALQ USP

Pror. Dr. Jose Antorio Frizzone

ESALQ/USP

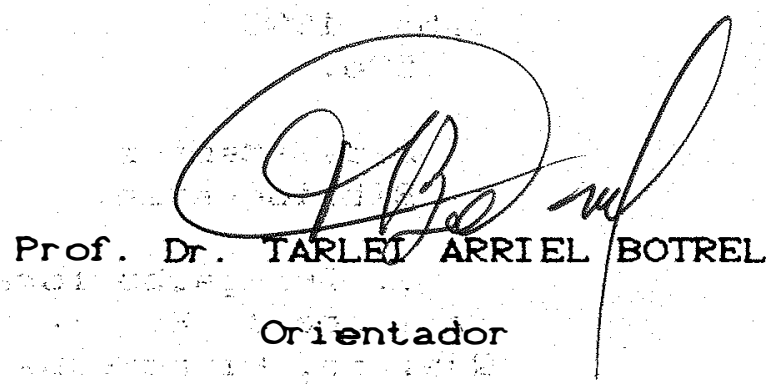


izi

A Leda, Rodrigo e Flávia 


\section{A G R A D E C I M E N T O S}

Ao professor Tarlei Arriel Botrel pela orientaçăo estimulo.

Ao professor Amauri de Almeida Machado pelo inestimável apoio e incentivo em todas as fases deste trabal ho.

Ao eng. agr. Milton Flávio Moura pelo apoio na realização do experimento.

Ao eng. agr. Francisco Nuevo, pelo apoio cessão do programa computacional para simulação de vazóes.

Ao CNPq, pela concessão de bolsa de estudo para a realização do curso.

Aos demais professores, colegas de curso e funcionários da ESALQ que de al guma forma contribuiram para que este trabalho fosse realizado. 
Página

COMI SSAO JULGADORA . . . . . . . . . . . . . . . . . . . . . . . ii

DEDI CATORI A . . . . . . . . . . . . . . . . . . . . . . ii

AGRADECIMENTOS . . . . . . . . . . . . . . . . . . . iv

SUMARIO . . . . . . . . . . . . . . . . . . . . . . . v v

LISTA DE FIGURAS ... . . . . . . . . . . . . . . . . . vi

LISTA DE TABELAS . . . . . . . . . . . . . . . . . . $x$

LISTA DE ABREVI ATURAS E ST MBOLOS.............. . . xi

RESUMO . . . . . . . . . . . . . . . . . . . . . . . $x i i$

SUMMARY . . . . . . . . . . . . . . . . . . . . . . xiv

1. INTRODUÇRO

2. REVISTO DE LITERATURA . . . . . . . . . . . . . . . . . . . . . . 3

2.1. Avallação da Uniformidade de Distribuição. . . . 4

2.1.1. Avaliação de Campo da Uniformidade de

Distribuição nos sistemas de Irrigação

Localizada... . . . . . . . . . . . . . 6

2. 2. Uniformidade de Emissăo . . . . . . . . . . . . 8

2.2.1. Variação na Fabricaçăo dos Emissores. . . . 11

2.2. 2. Número de Emissores por Planta. . . . . . 12

2. 3. Uniformidade Estatistica . . . . . . . . . . 13

3. METODOLOOTA . . . . . . . . . . . . . . . . . . . . . . . 17

3.1. Descriçao dos Métodos Utilizados na Avaliaçăo da Uniformidade . . . . . . . . . . . 18

3.1.1. Uniformidade de Emissão . . . . . . . . . . 18

3.1.2. Uniformidade Estatistica . . . . . . . . . 19 
3. 2. Simul ação de Vazóes . . . . . . . . . . . . . . . 20

3. 3. Avali ação e Comparação dos Métodos Aplicados . 21

3. 4. Procedimento de Aval1 açăo de Campo . . . . . . . 23

3.4.1. Descrição do Sistema de Irrigação Avali ado em Campo . . . . . . . . . . . . . 23

3. 4.2. Metodologia da Coleta de Vazð́es . . . . . . 24

4. RESULTADOS E DISCUSSÃO . . . . . . . . . . . . . . . 27

4.1. Valores de uniformidade obtidos a partir de simul ação . . . . . . . . . . . . . . . . . 27

4. 2. Comparą̧̃̃o dos métodos . . . . . . . . . . . . . 29

4.2.1. Aspecto metodologico............. . 29

4.2.2. Comportamento em relação a análise do censo: 30

4.2. 3. Comportamento em relaçăo ao CV . . . . . . . 30

4.3. Valores de uniformidade obtidos no levantamento de campo e comparação com os valores estimados por regressão .. . . . . . . . . . . . . 30

5. CONCLUSAO . . . . . . . . . . . . . . . . . . . . . 49

REFERENCI AS BIBLIOGRAFICAS . . . . . . . . . . . . . . . 50 


\section{LISTA DE FIGURAS}

Página

Figura 1 - Uniformidade $x \mathrm{CV}$ para tamanho amostral de 12 emissores; emissor A.

Figura 2 - Uniformidade $x$ CV para tamanho amostral de 18 emissores; emissor $A$.

Figura 3 - Uniformidade $x$ CV para tamanho amostral de 24 emissores; emissor

A. 34

Figura 4 - Uniformidade $x$ CV para tamanho amostral de 48 emissores; emissor A.

Figura 5 - Uniformidade $\times$ CV para tamanho amostral de 64 e 66 emissores; emissor A. . . . . . . 35

Figura 6 - Uniformidade $x$ CV para valores dos censos; emissor A. . . . . . . . . . . . . . 35

Figura 7 - Uniformidade $\times$ CV para tamanho amostral de 12 emissores; emissor B. . . . . . . . . 36

Figura 8 - Uniformidade $\times C V$ para tamanho amostral de 18 emissores; emissor B. . . . . . . . . 36

Figura $\theta$ - Uniformidade x CV para tamanho amostral de 24 emissores; emissor $B$

Figura 10 - Uniformidade $x$ CV para tamanho amostral de 48 emissores; emissor $B$.

Figura 11 - Uniformidade $\times C V$ para tamanho amostral de 64 e 66 emissores; emissor B 38

Figura 12 - Uniformidade $\times C V$ para valores dos censos: emissor $B$. 
Figura 13 - Uniformidade de emissão (UE) e uniformidade de emissão absoluta CUE $_{a}{ }^{2} \times$ tamanho amostral. $C V=4 \%$; emissor A. ...... . . 39

Figura 14 - Uniformidade de emissão (UE) e uniformidade de emissão absoluta $\left(U E_{a}\right) \times$ tamanho amostral. $C V=8 \%$; emissor $A$.

Figura 15 - Uniformidade de emissão (UE) e uniformidade de emissão absoluta $\left(U E_{a}\right) \times$ tamanho amostral. $C V=12 \% ;$ emissor $A$

Figura 16 - Uniformidade de emissao (UE) e uniformidade de emissão absoluta $\left(U E_{a}\right) \times$ tamanho amostral. $C V=16 \%$; emissor $A . . . . . .$.

Figura 17 - Uniformidade de emissão (UE) e uniformidade de emissão absoluta $\left(\mathrm{UE}_{a}{ }^{2} \times\right.$ tamanho amostral. $C V=20 \%$; emissor A. . . . . . . .

Figura 18 - Uniformidade de emissão (UE) e uniformidade de emissão absoluta $\left(U E_{a}\right) \times$ tamanho amostral. $C V=4 \%$; emissor $B$.

Figura 19 - Uniformidade de emissăo (UE) e umiformidade de emissão absol uta CUE $_{a}{ }^{2} \times$ tamanho amostral. $\mathrm{CV}=8 \%$; emissor $\mathrm{B}$.

Figura 20 - Uniformidade de emissão (UE) e uniformidade de emissão absoluta $\left(U E_{a}\right) \times$ tamanho amostral. $C V=12 \%$; emissor $B$.

Figura 21 - Uniformidade de emissão (UE) e uniformidade de emissão absoluta $\left(U E_{a}\right) \times$ tamanho amostral. CV = 16\%; emissor B. . . . . . . 
Figura 22 - Uniformidade de emissão (UE) e uniformidade de emissão absoluta $\left(U E_{a}\right) \times$ tamanho amostral. $\mathrm{CV}=20 \%$; emissor B. . . . . . 43

Figura 23 - Uniformidade estatistica $\left(U_{s}\right) \times$ tamanho amostral. $C V=4 \%$; emissor $A$.

Figura 24 - Uniformidade estatistica $\left.\mathrm{CU}_{\mathbf{s}}\right) \times$ tamanho amostral, $C V=8 \%$; emissor $A$.

Figura 25 - Uniformidade estatistica $\left(U_{s}\right) \times$ tamanho amostral. $\mathrm{CV}=12 \%$; emissor $\mathrm{A}$.

Figura 26 - Uniformidade estatistica $\left(U_{8}\right) \times$ tamanho amostral. $\mathrm{CV}=16 \%$; emissor A. . . . . . . 45

Figura 27 - Uniformidade estatistica $\left(U_{s}\right) \times$ tamanho amostral. CV = 20\%; emissor A. . . . . . . 46

Figura 28 - Uniformidade estatistica $\mathrm{CU}_{8}{ }^{2} \times$ tamanho amostral. $\mathrm{CV}=4 \%$; emissor B. . . . . . 46

Figura 29 - Uniformidade estatistica $\left(U_{5}\right) \times$ tamanho amostral. $C V=8 \%$; emissor B. . . . . . . 47

Figura 30 - Uniformidade estatistica $\mathrm{CU}_{8}{ }^{2} \times$ tamanho amostral. $C V=12 \%$; emissor B. . . . . . . 47

Figura 31 - Uniformidade estatistica $\left(U_{0}\right) \times$ tamanho amostral. $C V=16 \%$; emissor B. . . . . . 48

Figura 32 - Uniformidade estatistica $\left(U_{0}\right) \times$ tamanho amostral. $\mathrm{CV}=20 \%$; emissor B. . . . . . . 48 


\section{LISTA DE TABELAS}

Página

Tabela 1 - Classificação para o coeficiente de variaçăo de fabricaçăo $(C V)$. . . . . . . . . 13

Tabela 2 - Tamanhos de amostra utilizados no cálculo

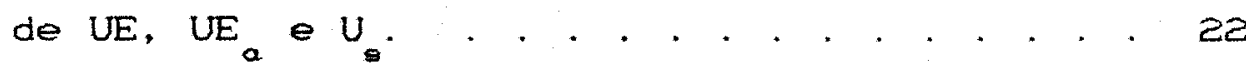

Tabela 3 - Equaçð̋es obtidas por regressão 1 inear

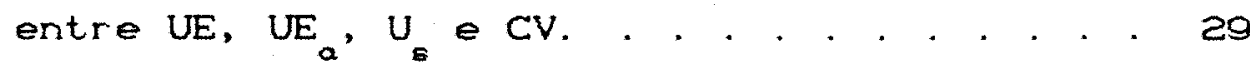

Tabela 4 - Valores de uniformidade obtidos no levantamento de campo. . . . . . . . . . . 31

Tabela 5 - Comparação entre os valores originais de uniformidade e os valores obtidos atraves das equaçoes propostas. . . . . . . . . . . 32 


\section{LISTA DE ABREVI ATURAS E ST́MBOLOS}

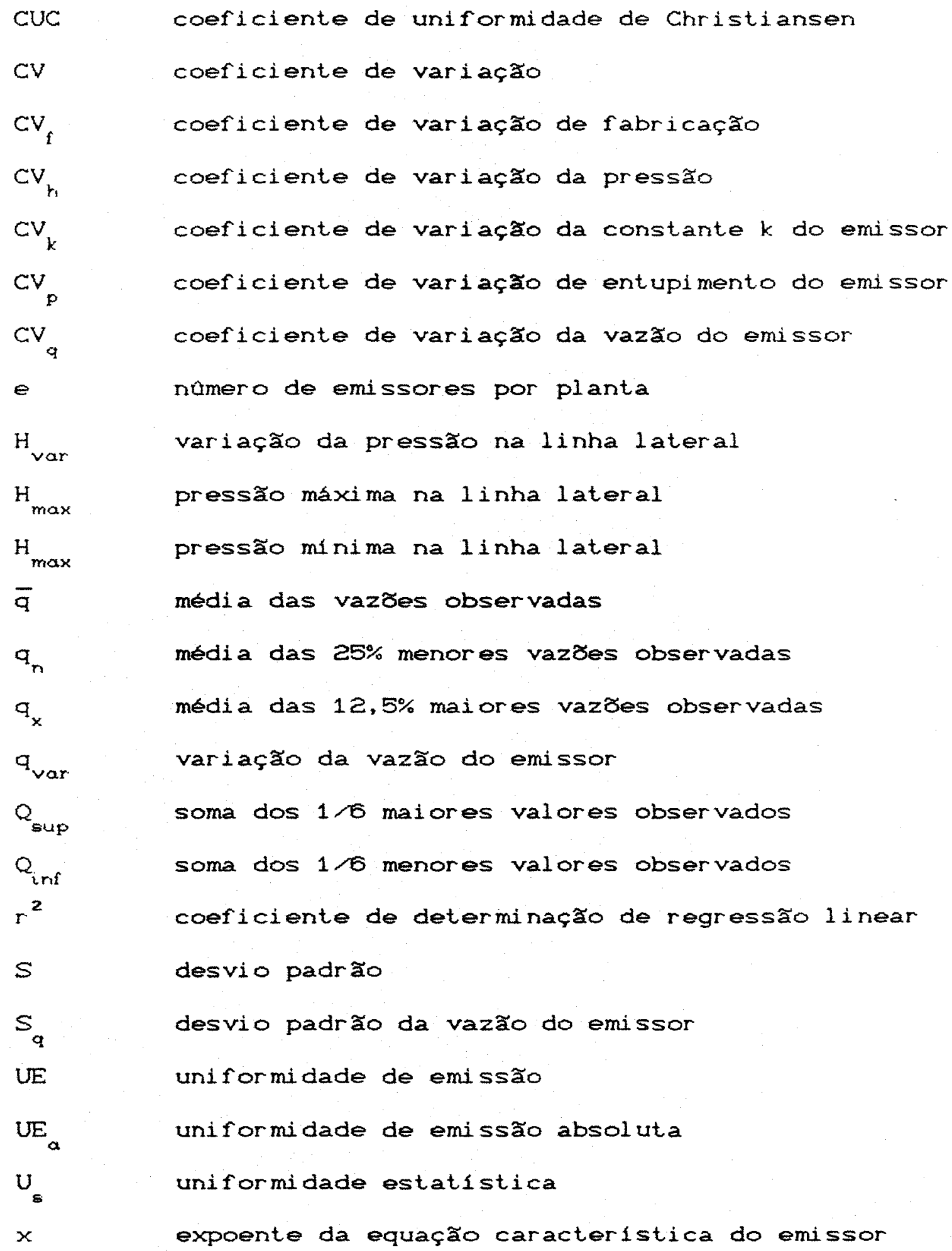




\title{
AVALIAÇÃO DA UNIFORMIDADE DE EMISSÃO E DA UNIFORMIDADE ESTATÍSTICA EM IRRIGAÇÃO LOCALIZADA
}

\author{
Autor: GILBERTO MANILLI FAVETTA \\ Orientador: Prof. Dr. TARLEI ARRIEL BOTREL
}

RESUMO

Visando a avaliaçăo dos principais métodos de estimativa da uniformidade de distribuição de água, foram simulados atraves de programa computacional conjuntos de valores de vazão de dois microaspersores distintos. Os valores de vazão foram gerados com diferentes graus de variabilidade, obtendo-se coeficientes de variaçăo CCV de $4 \%$ a $20 \%$, em intervalos de $1 \%$. Para cada conjunto foi calculada a uniformidade pelos métodos de uniformidade de emissão (UE), uniformidade de emissão absoluta $\left(U E_{a}\right)$ e uniformidade estatistica $\left(U_{s}\right)$ em diferentes tamanhos amostrais e também no censo de cada conjunto crelação completa de todas vazชes?.

Foram feitas regressoes lineares entre os valores de uniformidade de cada método calculados com base nos censos, obtendo-se altos coeficientes de determinação. Foram avaliadas tambem as uniformidades das vazóes de dois sistemas de irrigação por microaspersão obtidas em campo pelos mesmos metodos já citados. Os valores obtidos foram compara- 
dos com os valores calculados atraves das equaçós propostas geradas por regressão, chegando-se a valores bastante proximos.

A uniformidade estatistica (U) revelou-se o melhor metodo para estimativa dos valores de uniformidade. As equaçōes propostas mostraram-se capazes de estimar o valor de uniformidade por qualquer dos tres metodos avaliados CUE, UE $E_{a} U_{a}$ a partir de um valor previamente conhecido de um outro desses mesmos métodos. 


\title{
EMISSION UNIFORMITY AND STATISTICAL UNIFORMITY EVALUATION IN LOCALIZED IRRIGATION
}

\author{
Author: Gilberto Manilli Favetta \\ Adviser: Prof. Dr. Tarlei Arriel Botrel
}

SUMMARY

Aiming the evaluation of the main uniformity estimation methods, groups of two flow emitters were simulated through computational program. Such flow groups were generated in different variability levels, resulting coefficients of variation from $4 \%$ up to $20 \%$, with intervals of $1 \%$. Uniformity was calculated from each group through the emission uniformity (UE), absolute emission uniformity (UE ${ }_{a}$. and statistical uniformity $\left(U_{s}\right)$ methods in different sample sizes and in the census (complete relation of all flows) of each group. Linear regressions were carried out from the uniformity values obtained in the censi, giving highs coefricients of determination.

It was also evaluated from field data the flow uniformity of two microsprinklers irrigation systems through the same methods already cited. The resulting values were compared to the calculated ones provided by the proposed regression equations, being quite similar.

Statistical uniformity $\left(U_{s}\right)$ was the best method in the estimation of uniformity values. The proposed equations were able to estimate the uniformity by means of the eval uated methods (UE, UE ${ }_{a} \in U_{\mathbf{a}}$ ). 


\section{INTRODUÇZOO}

Os sistemas de irrigação localizada têm apresentado uma importancia crescente no cenario agricola brasileiro, com aplicação voltada principalmente à horticultura.

A principal finalidade da irrigaçăo localizada e o suprimento de água e nutrientes para as plantas com uma frequencia e volume adequados as suas necessidades. A irrigação localizada e também vastamente reconhecida na bibliografia como uma maneira eficiente de aplicaça de fertilizantes às culturas.

- acompanhamento do desempenho do sistema de irrigação ao longo de sua vida útil e importante para a obtenção de informaçós essenciais às atividades de manutenção e manejo do sistema.

A uniformidade de distribuição dos emissores - parametro que melhor caracteriza o desempenho de um sistema de irrigação localizada, sendo importante para a comparação com a uniformidade do sistema de irrigação prevista em projeto, para aperfeiçoar o manejo da irrigaça o da fertirrigaçăo e para a deteçăo de problemas que estejam ocorrendo com o equipamento. 
A uniformidade do sistema de irrigaçăo localizada é basicamente resultante da variação das vazbes dos emissores. Existem atualmente diferentes metodologias de avaliação da uniformidade de aplicaçăo nos sistemas de irrigação localizada.

Neste trabalho foram avaliadas metodologias baseadas em duas concepçoes de avaliação da uniformi dade: o conceito de uniformidade de emissão e o concelto de uniformidade estatistica. A avaliação dos métodos foi baseada na simulação de vazßes atraves de programa computacional. Foram simulados conjuntos de vazóes com 17 diferentes graus de uniformidade, sendo esse processo aplicado em dois sistemas de irrigação distintos. Os conjuntos de vazões simuladas foram analisados tambem em diferentes niveis amostrais.

Os resultados obtidos a partir dos dados de vazão simulados for am avaliados em dados de vazão obtidas a campo em dois sistemas de irrigação distintos. 


\section{REVISÃO DE LITERATURA}

Segundo JAMES (1988), o desempenho de um sistema de irrigação é determinado por trés parâmetros: eficiencia de aplicação, uniformidade de distribuição de água e adequacidade da irrigação.

Ainda segundo esse autor, o conceito de eficiência numa área irrigada é definido como a porcentagem de agua aplicada que e beneficamente utilizada para irrigaçăo. A uniformidade de aplicação descreve a regularidade com que um sistema de irrigação distribui a água numa determinada área e, finalmente, a adequacidade da irrigação é a porcentagem da área que recebe suficiente quantidade de água para manter a produtividade e a qualidade da produção agrícola em um nivel económico.

Entretanto, conforme relatam BRALTS et al. (1987), apesar da avaliaçăo de um sistema de irrigaça localizada envolver outros aspectos alem da uniformidade de vazão do emissor, a estimativa precisa da uniformidade do sistema provavelmente o indicador mais importante do seu desempenho. Segundo NAKAYAMA (1981), informaçסes referentes à vazão dos emissores e sua uniformidade são essenciais para 
- dimerisionamento e manejo dos sistemas de irrigaçăo localizada.

Nesse mesmo raciocinio, PIZZARRO (1986) observa que a uniformidade um parametro que caracteriza todo sistema de irrigação e que tem efeitos diretos tanto no projeto como no funcionamento dos equipamentos.

\subsection{Avaliação da Uniformidade de Distribuição}

Segundo VERMEIREN \& JOBLING (1984), nos sistemas de irrigaçăo localizada a água e conduzida por uma rede de tubulaçóes ate o ponto de infiltração no solo. Por esse motivo, a uniformidade da vazão individual dos emissores do sistema dá uma boa ideia da uniformidade de distribuição.

CHRISTIANSEN (1942) propos um coeficiente de uniformidade (CUC) como forma de avaliaçăo quantitativa da uniformidade em sistemas de irrigação por aspersão. Este coeficiente é baseado na soma dos desvios absolutos de cada observação a partir da média (SOLOMON \& KELLER, 1978$).$

HART \& REYNOLDS (1965) estudaram a relação entre cuc e o desvio padrão, e verificaram que a distribuição dos valores das laminas observadas na irrigação por aspersão aproxima-se da curva de distribuição de Gauss, para um CV superior a $60 \%$.

Nos sistemas de irrigação localizada a descarga dos emissores é influenciada pelas seguintes variaveis: projeto do emissor, padröes de fabricação, perdas de carga na rede hidráulica, variaçôes topográficas na área irrigada, 
quartidade e grau de entupimento de emissores, variaçáo da temperatura da agua dentro do sistema, presença de ar na rede hidráulica e ainda de eventuals perfuraç⿸es na tubulação. Segundo SOLOMON (1985) o entupimento dos emissores, o número de emissores por planta e a variação de fabricação dos emissores são os fatores mais significantes influenciando a uniformidade dos sistemas de irrigação localizada. Neste mesmo sentido, SAMMIS \& WU (1985) citam que a uniformidade de distribuiçăo depende da uniformidade de fabricação, do projeto hidráulico e da manutenção do sistema de irrigação.

Segundo BRALTS (1986), apesar dos sistemas de irrigação localizada apresentarem alto potencial de eficiencia, fatores como dimensionamento inadequado, assim como manejo e manutençăo deficientes, podem ocasionar baixos Indices de eficiéncia. Para compensação destes baixos Indices, o irrigante se ve obrigado a fazer uso intensivo da irrigação, que poderá ocasionar perda de água, nutrientes e energia. SAMMIS \& WU (1985) relatam que a manutenção inadequada do sistema de irrigaçăo pode reduzir drasticamente a uniformidade de distribuição, resultando em aumento do volume de água aplicado.

BRALTS (1986) menciona que nenhuma equação para dimensionamento de sistemas de irrigação localizada, que incluisse os diversos fatores que afetam a uniformidade da vazão dos emissores, havia sido proposta ate então. 
2.1.1. Avaliação de Campo da Uniformidade de Distribuição nos Sistemas de Irrigação Localizada Segundo BRALTS (1986) E BRALTS et al. (1987) a avaliação de campo nos sistemas de irrigação localizada e importante pelos seguintes motivos:

i. Fornece informaçós importantes para o manejo do sistema. ii. permite determinar com que eficiencia o sistema está sendo operado e se as especificaçzes de uniformidade de vazão dos emissores previstas em projeto estão sendo obtidas. A avaliaçăo permite ainda o monitoramento do desempenho do sistema quando realizada periodicamente.

iir. possibilita a determinação da eficiencia com que o sistema pode chegar a operar e se ele pode ser melhorado.

iv. E uma ferramenta de diagnóstico da operaça do sistema e seus componentes, e ainda uma ferramenta para a adoçăo de medidas corretivas se necessario.

v. fornece informaçōes que auxiliam os projetistas no dimensionamento de outros sistemas.

vi. fornece informaçðes que permitem comparar varios métodos, sistemas e procedimentos operacionais como base para decişres económicas.

MERRIAN et al. (1983) afirmam que as condiçôes em que um sistema de irrigação está sendo operado (eficiencia de distribuição atual), as condiços em que pode vir a operar (eficiencia de distribuiçăo potencial) ou alnda a conírmaçăo da eficiencia prevista em projeto, somente podem ser obtidas por avaliação de campo. 
Tres metodos tém sido empregados na avaliaçăo de sistemas de irrigaçăo localizada:

- Conceito de uniformidade de emissão CKELLER \& KARMELI , 1974)

- Conceito da variaçăo da vazão do emissor CWU \& GITLIN, 19743

- Conceito de uniformidade estatistica CBRALTS et al. . $1981 \mathrm{a}, \mathrm{b})$

Segundo BRALTS (1986), o metodo de avaliação de campo proposto por WU \& GI ILIN (1974) para determinação da uniformidade de emissão uma estimativa da variação da vazão dos emissores baseada na variação de pressão das linhas laterais. Esse metodo consiste em encontrar as pressöes máxima e minima nas linhas laterais entăo calcular a variação da vazão dos emissores pelas eq. 1 e 2.

$$
\begin{aligned}
& q_{\text {var }}=100\left[1-\left(1-H_{\text {var }}\right)^{x}\right] \\
& H_{\text {var }}=\frac{H_{\text {max }}-H_{\text {min }}}{H_{\text {max }}}(1)
\end{aligned}
$$

sendo:

$$
\begin{aligned}
& q_{\text {var }} \text { - variação da vazão do emissor } \\
& H_{\text {var }} \text { - variação da pressão na linha lateral } \\
& H_{\text {max }} \text { - pressão máxima na linha lateral } \\
& H_{\text {min }} \text { - pressão minima na linha lateral do } \\
& x \text { - expoente da equação caracteristica do } \\
& \text { emissor } \left.C q=k H^{x}\right)
\end{aligned}
$$


A maior limitaçáo desse método năo considerar a variação da vazão devido a uniformidade de rabricação e ao grau de entupimento, que podem ser significativos na uniformidade do sistema, conforme menciona BRALTS (1987).

\section{2. Uniformi dade de Emissão}

O conceito de uniformidade de emissăo, UE, foi originalmente apresentado por KELLEF \& KARMELI em 1974, sendo a sua definição baseada na razão entre as vazơes minima e média dos emissores.

MERRIAN et al. (1983) utilizam os termos uniformidade de distribuição e uniformidade de emissão como sinónimos em seu trabalho. JAMES (1988) adota o nome de uniformidade de distribuiçăo para o conceito aqui apresentado de UE.

UE é expressa peía eq. 3.

$$
U E=100 \frac{q_{n}}{\bar{q}}
$$

sendo:

$$
\begin{aligned}
& \text { UE - uniformidade de emissão } \\
& q_{n} \text { - media das } 25 \% \text { menores vazöes observadas } \\
& \bar{q} \text { - media de todas as vazóes observadas }
\end{aligned}
$$

Esse conceito fol baseado ná premissa de que o objetivo primário de um sistema de irrigação e assegurar a aplicą̧ão de uma quantidade minima de água na area irrigada, conforme observaram SOLOMON \& KELLER (1978).

De acordo com PIZARRO (1986). UE pode ser uti- 
lizada tanto para fins de dimensionamento do sistema como para sua avaliação de campo. No caso de dimensionamento. ao contrário da avaliaçăo de um sistema já instalado, a uniformidade é uma condiçăo que se impơe.

Segundo CUENCA (1989), para efeito de dimensionamento, $q_{n}$ passa a ser a vazão minima do emissor e $\bar{q}$ a média da vazão de projeto do emissor. A vazão minima do emissor corresponde ao ponto de menor pressão no sistema de distribuiçæ̃o.

PIZARRO (1986) observa ainda que quanto maior - valor de UE mais caro fica o equipamento de irrigação, ja que para uma menor dispersão nas vazơes, a distribuição de pressbes na rede hidraulica precisa ser mais uniforme, o que exige maior diámetro nas canalizaçôes, laterais mais curtas, maior investimento em reguladores de pressão, etc.

Posteriormente, conforme observou BRALTS (1986), a eq. 3 foi modificada e redefinida de forma a incluir o coeficiente de variação de fabricação (CV), e o número de emissores por planta (e). Desta forma, a estimativa da uniformidade de emissão para fins de dimensionamento do sistema pode ser feita pela eq. 4.

KELLER \& KARMELI (1974), propuseram uma forma modificada da equação de UE, denominada uniformidade de emissão absoluta, UE ${ }_{a}$, que inclui as razỡes das vazões maxima e minima dos emissores com a media. UE a expressa pela eq. 5 . 


$$
U E=100\left(1-1,27 \cdot e^{-0,5} \cdot C V v_{1}\right] \frac{q_{n}}{\bar{q}} \quad(4)
$$

sendo:

UE - uniformidade de emissão

- - número de emissores por planta

$q_{n}$ - média das $25 \%$ menores vazores observadas

$\bar{q}$ - media das vazß̈es observadas

$\mathrm{CV}_{\mathrm{f}}-$ coeficiente de variaçăo de fabricaçăo

$$
U E_{a}=100 \cdot \frac{1}{2}\left(\frac{q_{n}}{\bar{q}}+\frac{\bar{q}}{q_{x}}\right] \quad(5)
$$

sendo:

$$
\begin{aligned}
& \text { UE - uniformidade de emissão absoluta, em } \\
& \text { porcentagem } \\
& q_{n} \text { - media das } 25 \% \text { menores vazoes observadas } \\
& q_{x} \text { - media das } 12,5 \% \text { maiores vazzes observadas } \\
& \bar{q} \text { - média das vazóes observadas }
\end{aligned}
$$

A principal desvantagem desse metodo, segundo BRALTS (1986), é a ausencia de fundamentos estatisticos. Por essa razão, os intervalos de confiança e a análise das causas de variação da vazão dos emissores não podem ser obtidos. Ainda segundo BRALTS (1887), o método proposto por KELLER \& KARMELI é uma forma modificada do sistema de ava1 iação do Soil Conservation Service (USDA.

o conceito de uniformidade de emissăo e descrito por MERRIAN et al. (1983) como "low quarter concept". tendo sido proposto pelo Soil Conservation Service e recomendado como padrão para comparação entre situaçães 
diferentes.

o procedimento de avaliaçăo de campo desse método consiste em se tomar amostras da vazáo dos emissores em 16 pontos simetricamente distribuidos na area de interesse.

BRALTS (1986) apresenta os seguintes
criterios para interpretaça dos valores de UE UE $\mathrm{UE}_{a}$
$90 \%$ ou maior: excelente
$80 \%$ a $90 \%: \quad$ bom
$70 \%$ a $80 \%: \quad$ regular
menor que $70 \%:$ ruim

\subsubsection{Variação na Fabricação dos Emissores}

De acordo com SOLOMON (1979), a variaça na fabricação dos emissores é um fator de grande influencia na uniformidade de distribuiçăo de um sistema de irrigação localizada. Deve ser levada em consideração na seleção do emissor e no dimensionamento do sistema, objelivando atingir niveis predeterminados de eficiencia. Ainda segundo este autor, o coeficiente de variaçăo de fabricação $(C V)$ e o parametro indicado para avaliaçăo das diferenças individuais entre emissores.

Segundo NAKAYAMA et al. (1979) o coeficiente de variação de fabricaça descreve a variaçă na vazáo em uma amostra de emissores novos operando em temperatura constante e na pressão de serviço do emissor.

SOLOMON (1979) menciona que $0 \mathrm{CV}_{\mathrm{f}}$ influen- 
ciado pelo projeto do emissor. pelos materials usados na sua construçăo e pelos cuidados aplicados na sua rabricaçăo controle de qualidade.

Ainda segundo SOLOMON (1979) a variação da vazão do emissor resultante da variaçăo de fabricaçăo assumida como tendo distribuiça normal. Este autor recomenda que o CV, seja definido pela razão entre o desvio padrão da vazão do emissor e a sua média, conforme descreve a eq. 6 .

sendo:

$$
C V_{1}=\frac{s_{q}}{\bar{q}} \quad(6)
$$

$$
\begin{aligned}
& C V_{1} \text { - coeficiente de variação de fabricação } \\
& S_{q} \text { - desvio padrão da vazão dos emissores } \\
& \bar{q} \text { - media das vazßes observadas }
\end{aligned}
$$

\section{A AMERICAN SOCIETY OF AGRICULTURAL ENGINEERS} (ASAE) recomenda a classificação da Tabela 1 para o CV.

\subsubsection{Número de Emissores por Planta}

De acordo com SOLOMON \& KELLER (1978), a variação da vazão total de um conjunto de emissores a variação individual de vazăo dos emissores. Do ponto de vista estatistico, quando há vários emissores por planta as variagós nas vazöes de cadá emissor tendem a se anular mutuamente. O desvio padrão da vazão total destinada a uma planta por um número de emissores (e) o desvio padrăo da vazão individual dos emissores dividido pela raiz quadrada de (e). 
Tabela 1 - Classificaçăo para o coeficiente de variação de fabricaçăo $(C V)$.

\begin{tabular}{|c|c|c|}
\hline Fonte de emissão & $\mathrm{CV}_{\mathrm{f}}$ & Classificaçăo \\
\hline Fonte puntual & $\begin{array}{rl} & <0,05 \\
0,05 & \text { a } 0,10 \\
0.10 & a 0,15 \\
& >0,15\end{array}$ & $\begin{array}{l}\text { bom } \\
\text { medio } \\
\text { marginal } \\
\text { inaceitavel }\end{array}$ \\
\hline Fonte linear & $\begin{array}{rl} & <0,10 \\
0,10 & a 0,20 \\
& >0,20\end{array}$ & $\begin{array}{l}\text { bom } \\
\text { médio } \\
\text { marginal a } \\
\text { inaceitável }\end{array}$ \\
\hline
\end{tabular}

Fonte: ASAE standards EF 405, 1985

\subsection{Uniformidade Estatistica}

O chamado conceito de uniformidade estatistica consiste numa abordagem da uniformidade de vazao dos emissores e da eficiéncia de distribuição baseada no coeficiente de variação da vazão (BRALTS et al., 1887). Esse conceito, aplicado à irrigação localizada, está apresentado, nos trabalhos de BRALTS (1986), BRALTS et al. (1981a,b, 1982 . 1987), BRALTS \& KESNER (1983) E BENAMI \& OFEN (1984). ESSa abordagem feita sobre a uniformidade de distribuiçăo permite oferecer metodologias para serem utilizadas tanto no dimensionamento de sistemas de irrigação como na sua avaliação de campo.

A uniformidade estatistica fol primeiramente apresentada por WILCOX \& SWAILES (1947) na avaliação de equipamentos de irrigaçáo por aspersão, sendo baseada no 
coeficiente de variaçăo (CV) da lamina aplicada. De acordo com BRALTS et al. (1987), uma abordagem estatistica identica pode ser feita para os sistemas de irrigação localizada. bastando a substituição das 1áminas, na conceituaçăo original, pela vazão dos emissores, resultando na eq. 7 .

$$
U_{s}=100\left(1-C V_{q}\right)=100\left(1-\frac{s_{q}}{\bar{q}}\right)(7)
$$

sendo:

$$
\begin{aligned}
& U_{s} \text { - uniformidade estatistica } \\
& C V_{q} \text { - coeficiente de variação da vazåo do emissor } \\
& S_{q} \text { - desvio padr zo da vazão do emissor } \\
& \bar{q} \text { - média das vazőes observadas }
\end{aligned}
$$

BRALTS \& KESNER (1983) propuseram um método de estimativa da uniformidade da vazão dos emissores baseado no CV a partir de dados medidos a campo. As vantagens desse método incluem a simplicidade nos levantamentos de campo a capacidade de estabelecer intervalos de confiança baseados na estimativa da uniformidade.

Neste método estimam-se o desvio padrão e a media, e a partir desses dois valores o CV. BRALTS \& KESNER (1983) avaliaram ainda que uma amostra de 18 vazöes observadas aleatoriamente são suficientes para a estimativa do desvio padrão atraves deste método.

Para estimativa do desvio padrão, BRALTS \& KESNER (1983) utilizam o método reportado por LATHROP (1961). Tal metodo utiliza a diferença entre dois valores retirados das extremidades da curva de distribuiçăo para es- 
timar o desvio padrão.

O conceito de uniformidade estatistica é baseado no coeficiente de variação da vazão dos emissores e trata a variação dessas vazores como uma combinação probabilistica dos fatores que a influenciam, conforme relatam BRALTS et al. (1987).

BRALTS et al. (1981a,b) mostraram que para emissores do tipo oriflcio, instalados em tubos de camara simples, os coeficientes de variação hidráulica e de fabricação são independentes e podem ser combinados num coeficiente único de variação. Posteriormente, BRALTS et al. (1987) passaram a apresentar o coeficiente de variação total do emissor como uma função dos coeficientes de variação parciais devidos a hidráulica, processo de fabricaçăo, número de emissores por planta e entupimento, dando origem a eq. 8 .

$$
C V_{q}=e^{-1 / 2}\left(C v_{p}^{2}+C v_{k}^{2}+x^{2} C v_{h}^{2}\right)^{1 / 2}(8)
$$

sendo:

$\mathrm{CV}_{q}$ - coeficiente de variação da vazão do emissor

CV - coeficiente de variação de entupimento do emissor

$C V_{k}$ - coeficiente de variação da constante $k$ de emissor

$C V_{b}$ - coeficiente de variação da pressão

x - expoente da equação caracteristica do emissor $\left(q=k H^{x}\right)$

e - numero de emissores por planta 
BRALTS et al. (1981a,b) recomendam o uso de U na avaliaçăo das linhas laterais de um sistema de irrigação localizada. A justificativa reside em que, nesta abordagem estatistica, todos os fatores que influenciam a uniformidade podem ser incluidos na estimativa final da uniformidade. Esses fatores são a perda de carga, desnivel topográfico, variação na fabricação dos emissores e entupimento.

O criterio geral para interpretação de $\mathrm{U}_{\mathbf{s}}$ é:

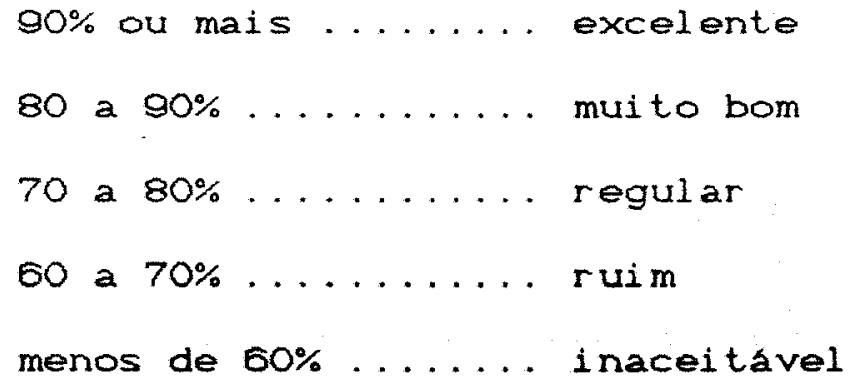




\section{METODOLOGIA}

Foram analisadas duas diferentes concepções de avaliação da uniformi dade em irrigaçăo localizada: o conceito de uniformidade de emissão e o conceito de uniformidade estatistica. A primeira foi estudada ainda sob suas duas versôes, uniformidade de emissão e uniformidade de emissão absoluta. As concepçoses for am avaliadas individualmente e comparadas entre si.

Neste trabalho a metodologia para analise e comparação dos metodos de cada concepção está baseada na sua aplicação em dados simulados de vazão de microaspersores.

Os resultados obtidos nesta avaliação foram comparados atraves da aplicação dos métodos descritos em duas populaçães de vazão obtidas em levantamento de campo em dois sistemas de irrigação distintos.

Define-se neste trabalho os seguintes termos:

- parcela hidráulica (ou parcela): menor area de um sistema de irrigação passivel de individualizaçăo no manejo.

- Iinha de derivação: tubulação da qual se ramificam as $1 i-$ nhas laterais. 
- linha lateral (ou lateral): tubulaça na qual há emissores instalados.

- unidade hidráulica: área abrangida pelas linhas laterais derivadas a partir de uma única linha de derivação e não superior a área de uma parcela.

3.1. Descrição dos Metodos Utilizados na Avaliação da Uni formidade

3.1.1. Uniformidade de Emissão

A uniformidade de emissão, UE, e dada pela divisão entre as $25 \%$ menores vazôes observadas a a média de todas as vazóes observadas.

Já a uniformidade de emissão absoluta, UE ${ }_{a}$, que e uma variação da uniformidade de emissão, pondera as $25 \%$ menores e as $12,5 \%$ maiores vazres, ambas relacionadas com a média da vazóes observadas.

A amostragem padrăo para UE e UE a preve que sejam medidas as vazões em 16 emissores tomados em pontos previamente determinados da area avaliada, sendo 4 emissores por lateral, para um total de 4 laterais assim distribuidas: primeira lateral da linha de derivaçăo, lateral a $1 / 3$ do comprimento da 1 inha de derivaçăo, lateral a $2 / 3$ do comprimento da linha de derivaça e última lateral. Os emissores de cada lateral são escolhidos segundo o mesmo criterio de distribuição: primeiro emissor, emissor a $1 / 3$ do comprimento da lateral, emissor a $2 / 3$ da lateral e último emissor da lateral. O calculo de UE e UEa feito pelas eq. 3 e 5. 


\subsubsection{Uniformidade Estatistica}

O conceito de uniformidade estatistica baseado no CV da vazão dos emissores, lembrando que o CV por sua vez é obtido a partir das estimativas da média e do desvio padrão. Neste trabalho optou-se por estimar o desvio padrăo pelo método de LATHROP ${ }^{1}(1961)$, sugerido por BRALTS \& KESNER (1983), que utiliza valores extraidos das caudas da curva de distribuição. Este metodo foi utilizado devido a sua capacidade de estimar de forma bastante simples e precisa o desvio padrão a partir das vazőes observadas.

A amostragem padrão preconizada por BRALTS \& KESNER (1983) preve que sejam medidas as vazơes em 18 emissores tomados aleatoriamente na unidade hidraulica de interesse. A estimativa do coeficiente de variaçao e dada pela eq. 9

$$
C V_{q}=0.667 \frac{\left(Q_{\text {sup }}-Q_{\text {inf }}\right)}{\left(Q_{\text {sup }}+Q_{\text {inf }}\right)} \quad(\theta)
$$

sendo:

$$
\begin{aligned}
& C_{q} \text { - coeficiente de variaçăo da vazăo do emissor } \\
& Q_{\text {sup - soma dos } 1 \text { to maiores valores observados }} \\
& Q_{\text {irf }} \text { - soma dos } 1 \text { /6 menores valores observados }
\end{aligned}
$$

Uma vez obtido o coeficiente de variaçăo, calcula-se o valor da uniformidade estatistica, $U_{s}$ definido pela eq. 7 .

${ }^{1}$ LATHROP, R.L. A quick but accurate aproximation to the standard deviation of a distribution. Journal of Experimental Education. 29(3):319-21, 1951. 
3. 2. Simul ação de Vazões

Como já mencionado, os métodos for am aplicados em conjuntos de vazão de microaspersores obtidos a partir de simulaçăo. Foram simulados conjuntos de vazão de dois emissores distintos, em diferentes graus de uniformidade.

A simulação foi feita atraves do programa computacional DIMLOC. EXE, el aborado por NUEVO (1992), nas seguintes condiçöes:

i. As caracteristicas dos dois microaspersores utilizadas na execuça do programa foram obtidas no ensaio realizado por BOTREL (1984). Os microaspersores empregados for am o Irtec rotativo e o Dantas MA 120 , que passam a ser aqui identificados respectivamente por $A$ e B.

ii. Cada modelo de microaspersor teve seus conjuntos de vazão simulados sob condiçres distintas de espaçamento número de emissores por parcela hidraulica. Esse procedimento visou obter valores de uniformidade a partir de sistemas de irrigação diferentes.

iii. Para cada microaspersor foram simulados 17 conjuntos de vazão com CV variando de 4 a $20 \%$ em intervalos de $1 \%$ Ctota1 izando portanto 34 conjuntos de vazôes simuladas para A e B). A alteração do CV foi obtida unicamente atraves do CV, que necessita ser informado ao programa.

iv. Para cada conjunto de vazóes simuladas for am calculados UE, UE $\mathrm{U}_{\mathrm{a}}$. Estes métodos foram ainda aplicados sobre o censo de cada conjunto. Define-se censo neste trabalho como - registro de todas as vazzes presentes em um conjunto de 
emissores. Os tamanhos de amostras utilizados para cada método estão apresentados na Tabela 2.

v. Para o metodo de $U_{s}$ a coleta de vazres fol feita aleatoriamente em todos os niveis amostrais.

vi. Para os métodos de UE $e$ UE as diferentes niveis amostrais foram coletados seguindo o mesmo principio contido na amostra padrão de 16 pontos: foi obedecida a estrategia de coleta da vazão em ponto no inicio, pontos intermediarios e ponto no fim de cada lateral, localizados em intervalos equidistantes. As laterais escolhidas para coleta também seguiram o mesmo criterio. Os pontos de coleta estão expostos na Tabela 2. Exemplificando para o nivel amostral de 36 pontos de coleta: foram amostradas vazóes de 6 laterais localizadas em pontos equidistantes na linha de derivação, incluindo a primeira e a última laterais. Em cada uma dessas 6 laterais for am coletadas as vazöes de 6 emissores, seguindose o mesmo criterio de equidistancia entre emissores.

\section{3. Avaliação e Comparação dos Métodos Aplicados}

Os processos de cálculo de cada metodo foram aplicados em cada um dos 34 conjuntos de vazăo obtidos por simulaçăo. Cada método foi aplicado utilizando-se diferentes tamanhos amostrais, com o objetivo de avaliar como se comportam os valores de uniformidade obtidos em função dessa variavel. Foi feita uma coleta distinta de dados para cada tamanho amostral utilizado. A avaliação foi feita, para cada valor de CV, elaborando-se graficos contendo o número de 
Tabela 2 - Tamanhos de amostra utilizados no cálculo de UE, $U E_{a} \odot U_{s}$

\begin{tabular}{|c|c|c|}
\hline \multicolumn{2}{|c|}{$U E \propto U E_{a}$} & $\mathrm{U}_{\mathrm{s}}$ \\
\hline $\begin{array}{c}\text { TAMANHO } \\
\text { DA } \\
\text { AMOSTRA }\end{array}$ & $\begin{array}{l}\text { PONTOS } \\
\text { DE } \\
\text { COLETA }\end{array}$ & $\begin{array}{l}\text { TAMANHO } \\
\text { DA } \\
\text { AMOSTRA }\end{array}$ \\
\hline 09 & $3 \times 3$ & OE \\
\hline 12 & $4 \times 3$ & 12 \\
\hline 12 & $3 \times 4$ & 18 \\
\hline 16 & $4 \times 4$ & 24 \\
\hline 18 & $6 \times 3$ & 30 \\
\hline 18 & $3 \times 6$ & 36 \\
\hline 24 & $8 \times 3$ & 42 \\
\hline 24 & $6 \times 4$ & 48 \\
\hline 24 & $4 \times 6$ & 54 \\
\hline 24 & $3 \times 8$ & 60 \\
\hline 32 & $8 \times 4$ & 66 \\
\hline 32 & $4 \times 8$ & $7 \hat{\mathrm{e}}$ \\
\hline 36 & $6 \times 6$ & censo ${ }^{2}$ \\
\hline 48 & $8 \times 6$ & \\
\hline 48 & $6 \times 8$ & \\
\hline${ }_{\text {censo }}^{64}$ & $8 \times 8$ & \\
\hline
\end{tabular}

1 o primeiro digito descreve o número de laterais amostradas e o segundo digito descreve o número de emissores amostrados em cada lateral.

2 o censo do microaspersor A engloba 336 emissores e o do microaspersor B engloba 240 emissores.

observaçós da amostra no eixo das abscissas e os valores de uniformidade no eixo das ordenadas. A comparaçao entre os dois diferentes métodos foi feita através de estatisticas descritivas.

Os valores de uniformidade obtidos pelos diferentes metodos com base no censo dos conjuntos de vazão serviram como valores de referencia para avaliaça da sensibilidade do método. A sensibilidade a capacidade do 
metodo de estimar a uniformidade adequadamente, sendo funçăo do metodo em si e do tamanho da amostra.

Na avaliação dos métodos foram utilizados graficos construidos a partir dos valores de uniformidade obtidos, tendo sido construidos gráficos distintos para os emissores $A$ e B. Em um primeiro tipo de gráficos são apresentados os valores de uniformidade CUE, $U E_{a}$ e $U_{s}{ }^{2}$ versus CV. mantendo-se $\mathrm{fixo}$ o tamanho amostral; em um segundo tipo de grafico apresenta-se os valores de uniformidade versus tamanho amostral, mantendo-se fixo o CV. Tanto UE como UE, por se tratarem de variaçōes da mesma metodologia, são apresentados conjuntamente nos graficos, enquanto $U_{s}$ épresentado individual mente.

Com a finalidade de avaliação do grau de correlação dos métodos entre si, e destes com o CV, foram feitas regresszes in neares utilizando-se os valores de uniformidade calculados com base no censo. For am feitas regressóes dos metodos entre si e versus CV, utilizando-se valores de ambos os emissores.

\section{4. Procedimento de Avaliação de Campo}

3.4.1. Descrição do Sistema de Irrigação Avaliado em Campo

A avaliação foi executada em um sistema de irrigação por microaspersão implantado na Fazenda Umuarama, localizada no municipio de Itapetininga, Estado de Sa Paulo, em Novembro de 1991. Foram analisados 2 tipos de mi- 
croaspersores: o tipo rotativo, auto-regulável, modelo DAN 2001. com vazao nominal de $201 / \mathrm{h}$ e 0 tipo difusor, autoregulável, modelo DANJET, com vazão nominal de $191 \mathrm{~h}$.

Foi adotada para avaliação de cada tipo de microaspersor uma unidade hidraulica de uma das parcelas que comprem o sistema de irrigação.

A cultura irrigada é um pomar de laranjeiras plantadas em espaçamento $(7 \times 4) \mathrm{m}$ e com um microaspersor por planta. Os microaspersores săo espaçados de $4 \mathrm{~m}$, cada um colocado no centro entre duas árvores de uma mesma linha de plantio.

A tubulação das Iinhas laterais é de polietileno de baixa densidade, com diámetro externo de $16 \mathrm{~mm}$ (13mm internos.

\section{4. 2. Metodologia da coleta de Vazões}

Descreve-se a seguir a metodologia adotada no levantamento das vazbes (censo) de microaspersores das unidades hidráulicas.

i. As unidades hidráulicas escolhidas para análise, que receberam a identificação de $1 e \mathrm{e}$, têm as seguintes caracteristicas:

unidade 1: 336 microaspersores DANJET, distribuidos em 12 laterais de 28 emissores cada uma.

unidade 2: 315 microaspersores DAN 2001 distribuidos em 15 laterais de 21 emissores cada uma. 
ii. Procedimento de medida.

- os emissores foram numerados em ordem crescente do inicio para ofim da linha lateral.

- as linhas laterais foram numeradas em ordem crescente do inicio para o fim da linha secundaria.

- na medida da vazão foram utilizadas provetas de vidro com capacidade de $500 \mathrm{ml}$, graduadas de 5 em $5 \mathrm{ml}$, permitindo leituras de $2.5 \mathrm{em} 2.5 \mathrm{ml}$.

- para coleta da vazão o microaspersor foi desconectado do suporte de fixação ao solo.

- o tempo de coleta da vazão foi de 60 segundos, controlado por cronometro analógico. Durante esse periodo de 60 segundos o microaspersor foi inserido dentro da proveta, de forma que nå houvesse respingos para fora da mesma.

- o sistema de filtragem foi limpo antes do período de coleta, visando evitar flutuaçoses na pressão da rede.

- Foram medidas as pressbes inicial e final de cada lateral após o termino da coleta de vazores de seus emissores. Para tal foi utilizado um manometro tipo Bourdon com escala com divisões a cada $20 \mathrm{kFa}$ e calibrado com manometro padrăo com precisão de $0,5 \%$. A leitura da pressão nos pontos iniciais de cada lateral foi feita com auxilio de um adaptador que, ligado ao manómetro por uma das extremidades, era conectado ao corpo do primeiro microaspersor da lateral, previamente desmontado.

- Não foram feitas repetiçöes nas coletas de vazão. Um levantamento preliminar mostrou ser desnecessário tal 
procedimento, pois os valores observados se repetiram.

- Em caso de dúvida sobre o valor observado, o procedimento de coleta foi repetido. Sendo o novo valor diferente do primeiro, repetiu-se a leitura uma terceira vez. o valor utilizado para o cálculo da uniformidade passava a ser então a média dos tres valores observados.

- Quando visualmente foi observado problema de entupimento (o que só ocorre em caso de entupimento severo), - emissor fai desmontado e limpo e so após foi feita a coleta da vazão. 


\section{RESULTADOS E DISCUSSÃO}

\subsection{Valores de uniformidade obtidos a partir de simul ação}

Săo apresentados a seguir os graficos contendo os valores de uniformidade obtidos a partir da simulaçăo de vazóes. Os graficos de UE. UE ${ }_{a}=U_{s}$ versus $C V$ são apresentados nas figuras 1 a 12 , para tamanhos amostrais de 12,18 , 24, 48, 64 e 66 emissores e censo (população completa). Os tamanhos amostrais 64 e 66 referem-se a um único grafico, sendo o tamanho amostral 64 utilizado para cálculo de UE e $\mathrm{UE}_{a}$ e o valor 66 utilizado para calculo de $\mathrm{U}_{\$}$. Os demais tamanhos amostrais são identicos para os métodos de estimativa de uniformidade utilizados CUE, UE $\mathrm{U}_{\mathbf{s}}$. Os gráficos de UE - UE versus número de emissores por amostra sao apresentados nas Figuras 13 a 22 , para CV de $4 \%, 8 \%, 12 \%, 16 \%$ e $20 \%$ A titulo de referencia, foram incluidos em cada grafico os valores correspondentes as uniformidades calculadas com base nos dados do censo. Os graficos das figuras 23 a 32 são similares, somente que apresentando $U_{s}$ no lugar de UE $e$ UE ${ }_{a}$. Também nestes graficos são apresentados, a titulo de 
referencia, os valores de uniformidade calculados com base nos dados do censo.

Para os diferentes graficos descritos são apresentados dados dos dois modelos de microaspersores ava1iados, $A$ e B. Deve ser notado nos graficos que a tendéncia é similar para ambos os modelos de microaspersores analisados, mesmo tendo sido impostas condiçöes diferentes na simu1 ação das respectivas vazöes.

Os gráficos mostram que, como já era de se esperar, quanto maior o tamanho da amostra melhor os métodos estimam a uniformidade, tomando-se por base a uniformidade calculada pelo censo.

Analisando-se os graficos de uniformidade $x \mathrm{CV}$ e possivel avaliar que $U_{s}$ e um método com maior sensibilidade do que UE e UE, uma vez que, mesmo para diferentes amostras em coleta e tamanho, resultam valores de uniformidade menos dispersos em relaçăo à referencia.

Na Tabela 3 são apresentadas as equaçß̋es obtidas por regressão linear entre UE, $U E_{a}$ e $U_{s}$ entre si e com CV, tomando-se por base os dados dos censos dos emissores A e B. Todas as regressbes executadas foram baseadas em 34 pontos de observaçôs. Nota-se al o alto coeficiente de determinaçăo obtido entre os metodos de uniformidade e destes com o CV. 
Tabela 3 - Equaç̧̃es obtidas por regressao linear entre UE. $U E_{a}, U_{s} \in C V$.

\begin{tabular}{|c|c|c|c|}
\hline $\begin{array}{l}\text { var. } \\
\text { dep. }\end{array}$ & $\begin{array}{l}\text { var. } \\
\text { indep. }\end{array}$ & $r^{2}$ & equação obtida \\
\hline$C V$ & UE & 0.99696 & $C V=75,76819+U E(-0,75427)$ \\
\hline UE & CV & 0.99696 & $U E=100,40385+C V(-1,32175)$ \\
\hline $\mathrm{CV}$ & $\mathrm{UE}_{a}$ & 0,99844 & $C V=83,68856+U E_{a}(-0.84857)$ \\
\hline$U E_{a}$ & $\mathrm{CV}$ & 0,99844 & $U E_{a}=98,60104+C V(-1,17661)$ \\
\hline $\mathrm{CV}$ & $\mathrm{U}_{\mathrm{s}}$ & 0.99910 & $C V=104,46142+U_{s}(-1,04638)$ \\
\hline $\mathrm{U}_{\mathrm{s}}$ & CV & 0,99910 & $U_{s}=99,82086+C V(-0,95482)$ \\
\hline UE & $\mathrm{U}_{\mathbf{s}}$ & 0.99815 & $U E=-37.79586+U_{E}(1,38450)$ \\
\hline $\mathrm{U}_{\mathrm{s}}$ & UE & 0,99815 & $U_{s}=27,41242+U E(0,72094)$ \\
\hline UE & $U E_{a}$ & 0,99746 & $\mathrm{UE}=-10,30951+\mathrm{UE}_{a}(1,12276)$ \\
\hline$U E_{a}$ & UE & 0,99746 & $U E_{a}=9,37365+U E(0,88840)$ \\
\hline $\mathrm{UE}_{a}$ & $\mathrm{U}_{\mathrm{a}}$ & 0,99920 & $U_{a}=-24,40025+U_{a}(1,23221)$ \\
\hline $\mathrm{U}_{\mathrm{s}}$ & $\mathrm{UE}_{a}$ & 0,99920 & $U_{s}=19,85654+U E_{a}(0,81090)$ \\
\hline
\end{tabular}

\section{2. Comparação dos métodos}

\subsubsection{Aspecto metodológico}

Para os valores baixos de CV os tamanhos amostrais padrå para UE, $U E_{a}$ e $U_{\text {a }}$ foram suficientes para a obtenção de um CV confiável. Quando a uniformidade porem baixa, desejavel que o tamanho amostral seja maior que aquele recomendado pelos citados métodos. Quanto ao processo de amostragem observou-se que a forma aleatória utilizada por $U_{\text {a }}$ conferiu maior sensibilidade ao método que a amostragem dirigida utilizada por UE e UE ${ }_{a}$ podendo-se atribuir esse comportamento também à forma de análise dos dados em cada metodo. 
4.2.2. Comportamento em relação a análise do censo O método da $U_{\text {s }}$ mostrou ser menos variável do que UE e UE a em relação aos valores obtidos pela análise do dados do censo.

\section{2. 3. Comportamento em relação an CV}

O método $U_{s}$ apresentou a capacidade de estimar valores de uniformidade com menor variabilidade em relação ao $\mathrm{CV}$ do que UE e UE $\mathrm{U}_{a}$ o que era esperado, uma vez que o cálculo de $U_{s}$ esta baseado no CV. Observe-se, todavia, que o CV utilizado para calculo de $U_{s}$ adota $S$ estimado atraves do metodo de Lathrop, enquanto o CV utilizado na comparacão com UE e UE adota $S$ calculado pela forma tradicional.

4.3. Valores de uniformidade obtidos no levantamento de campo e comparação com os valores estimados por regressão

Os valores de uniformidade obtidos na a valiação de campo estão descritos na Tabela 4 . Esses valores foram comparados com os valores de uniformidade estimados através das equaços da Tabela 3 , para verificaça da validade das mesmas. Os altos coeficientes de determinacão $\left(r^{2}\right)$ obtidos na regressão entre cada um dos metodos entre si indica a possibilidade de estimativa da uniformidade por um dos tres metodos a partir de um dos outros mesmos metodos. O resultado da aplicaça desse processo nos dados coletados a 
campo confirma a sua validade. A Tabela 5 apresenta os valores de uniformidade obtidos atraves dessas duas formas, estando apresentado a seguir um exemplo de seu uso:

- Emissor: DAN 2001

- Valor a ser determinado: UE

- Valor conhecido: $U_{s}=94,75$ cvalor calculado pela forma convencional do método e apresentado na Tabela 4 ).

- Determinação do valor de UE: a aplicação do valor conhecido de $U_{s}$ na equação da Tabela 3 , que correlaciona UE com $U_{s}$ $\left(U E=-37,79586+U_{s}(1,38450)\right)$, sendo UE a variável dependente $e U_{s}$ a variável independente, resulta na uniformidade apresentada na quarta coluna/segunda linha dá Tabela 5, ou seja, 93,39. A diferença entre o valor calculado pela equação obtida por regressão e valor calculado da forma convencional do método estão apresentados, em valores absoluto e porcentual, nas duas ultimas colunas da Tabela 5 (neste exemplo, $-1,60$ e $-1,72 \%$ respectivamente).

Tabela 4 - Valores de uniformidade obtidos no levantamento de campo

\begin{tabular}{lcc}
\hline Emissor & Método & Valor Obtido \\
\hline DAN 2001 & UE & 90,84 \\
DAN 2001 & $U_{a}$ & 91,60 \\
DAN 2001 & $U_{s}$ & 94,75 \\
DAN JET & UE & 92,47 \\
DAN JET & $U_{a}$ & 91,80 \\
DAN JET & $U_{s}$ & 96,19 \\
\hline
\end{tabular}


Tabela 5 - Comparação entre os valores observados de uniformidade e os valores obtidos atraves das equaçóes propostas.

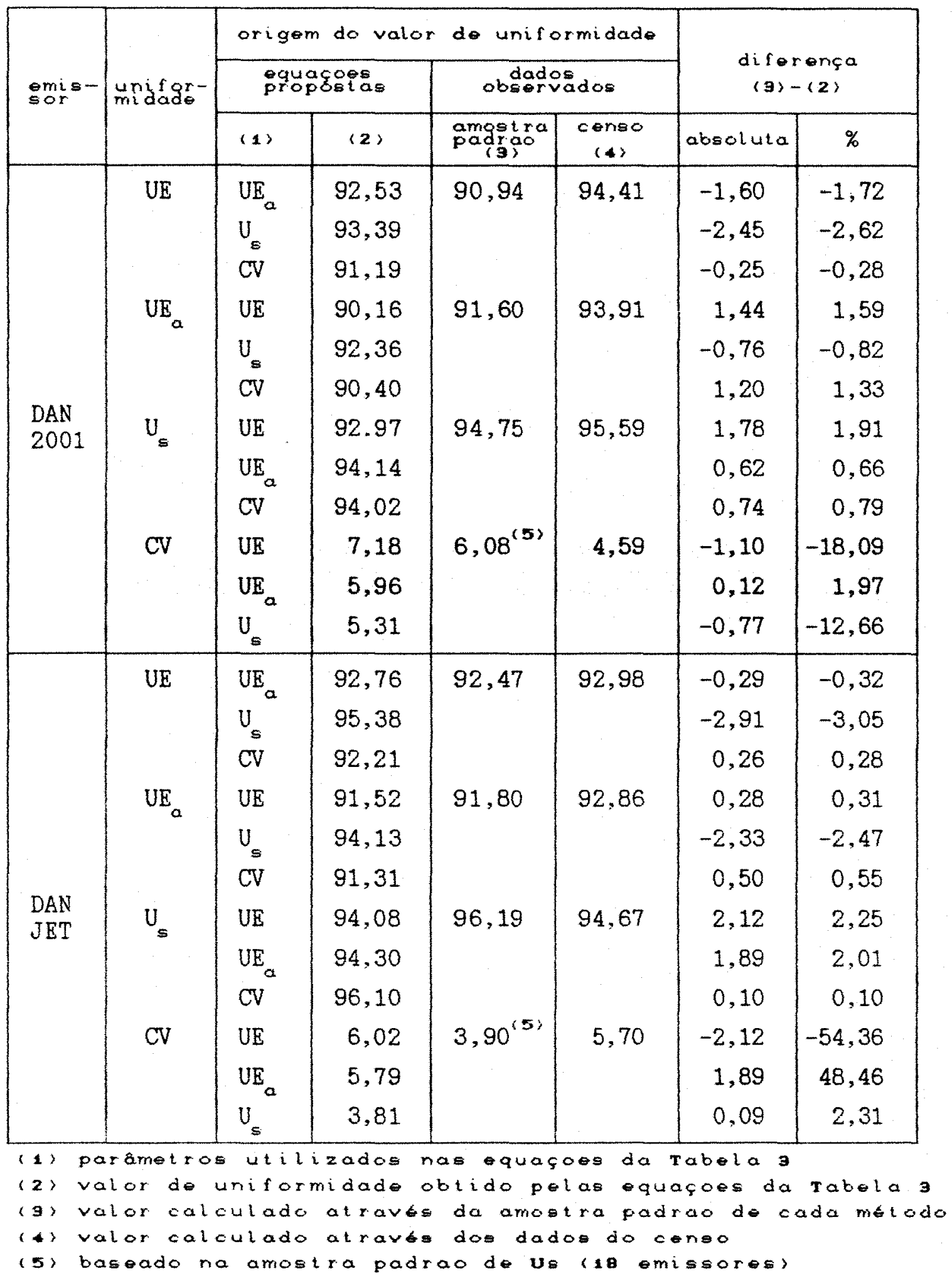




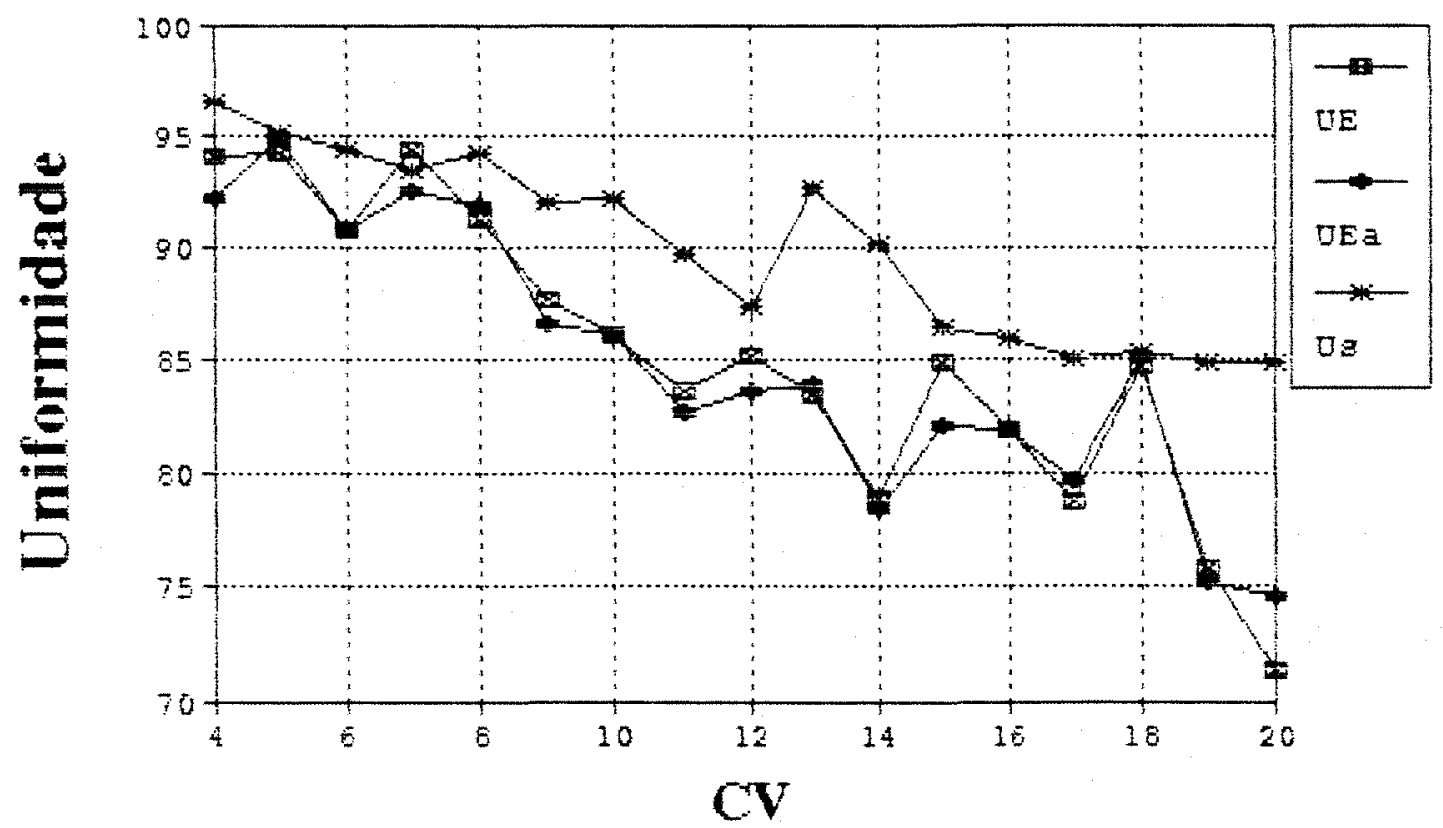

Figura 1 - Uniformidade $x$ CV para tamanho amostral de 12 emissores; emissor A.

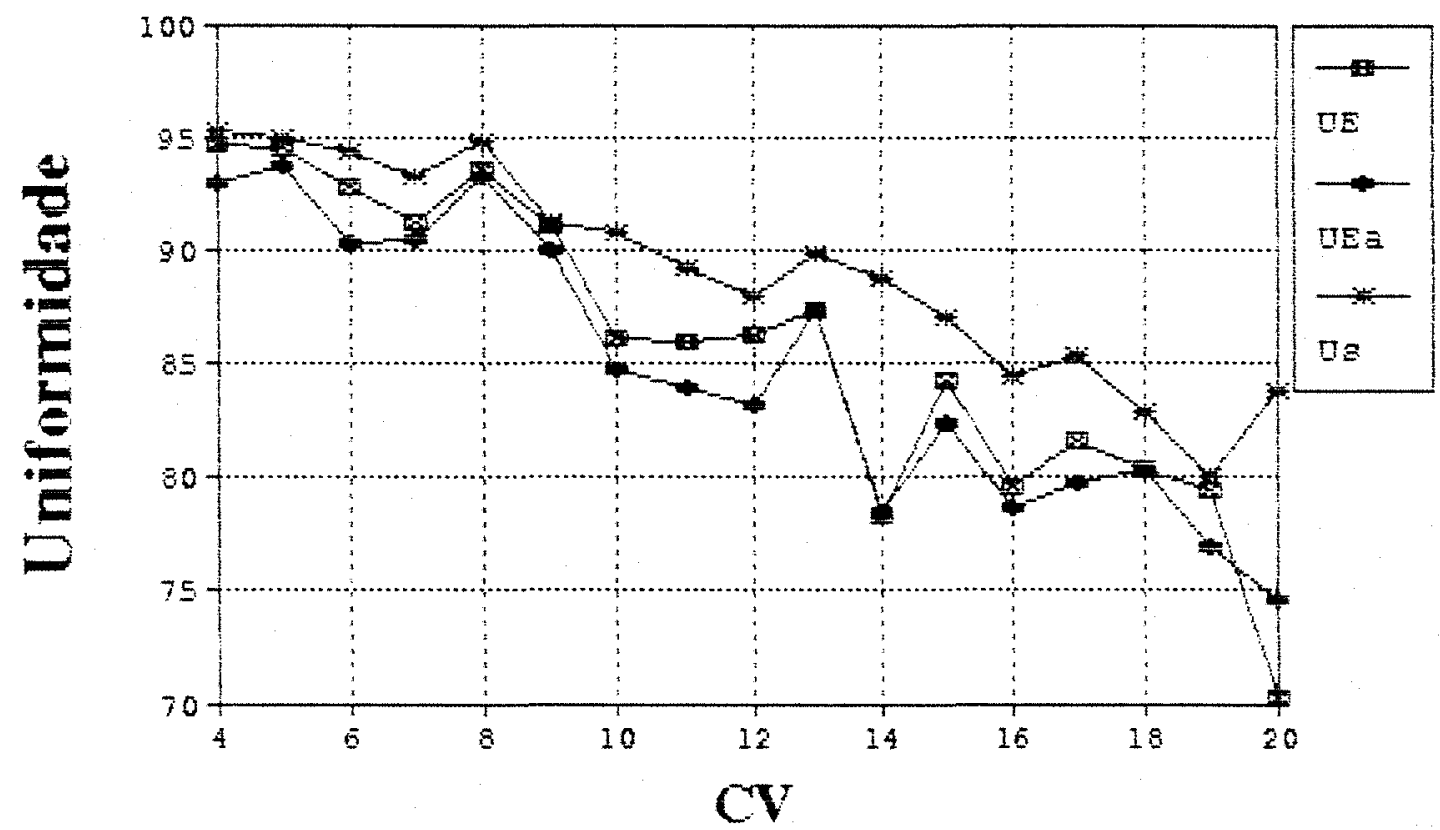

Figura 2 - Uniformidade $x$ CV para tamanho amostral de 18 emissores; emissor A. 


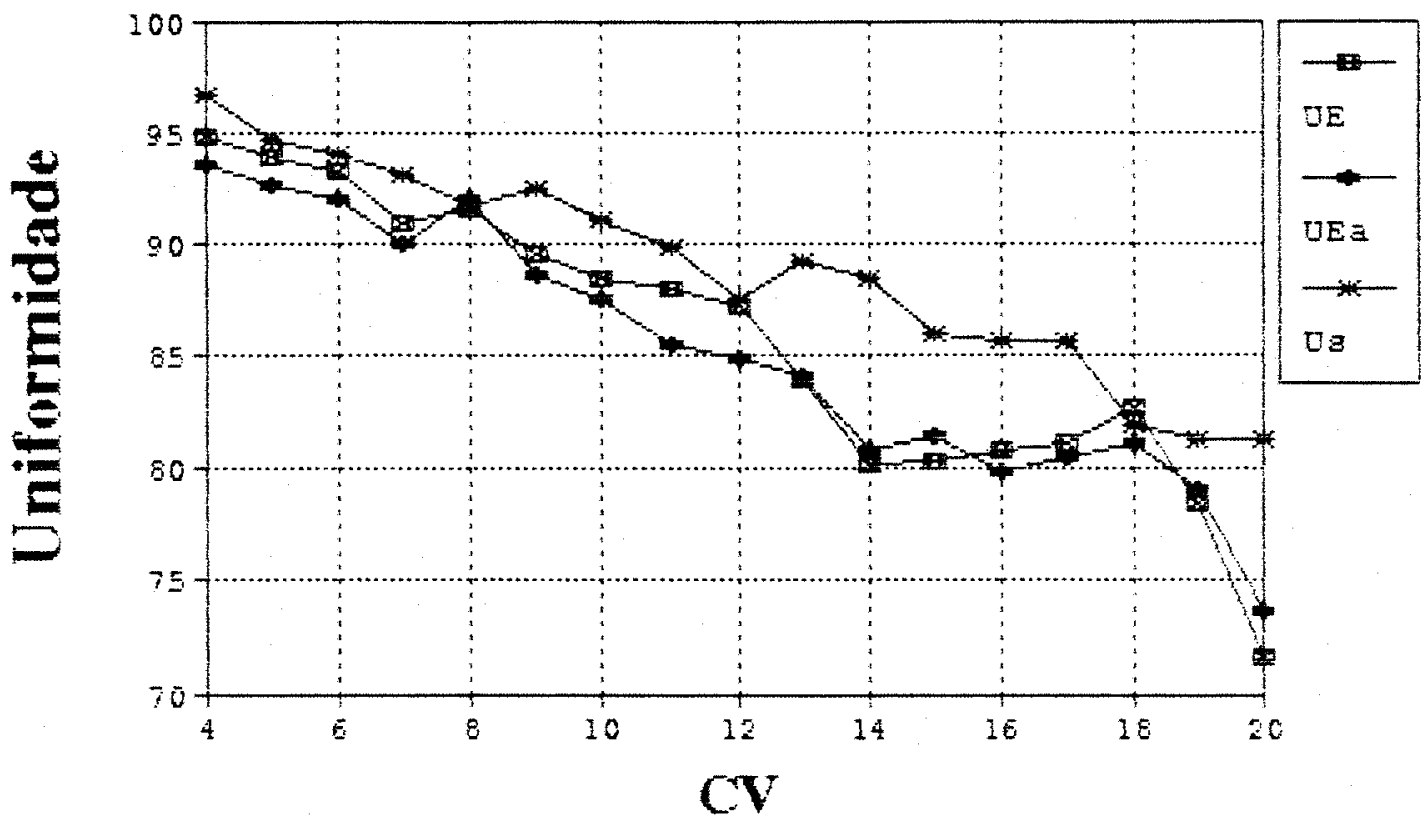

Figura 3 - Uniformidade $x$ GV para tamanho amostral de 24 emissores; emissor A.

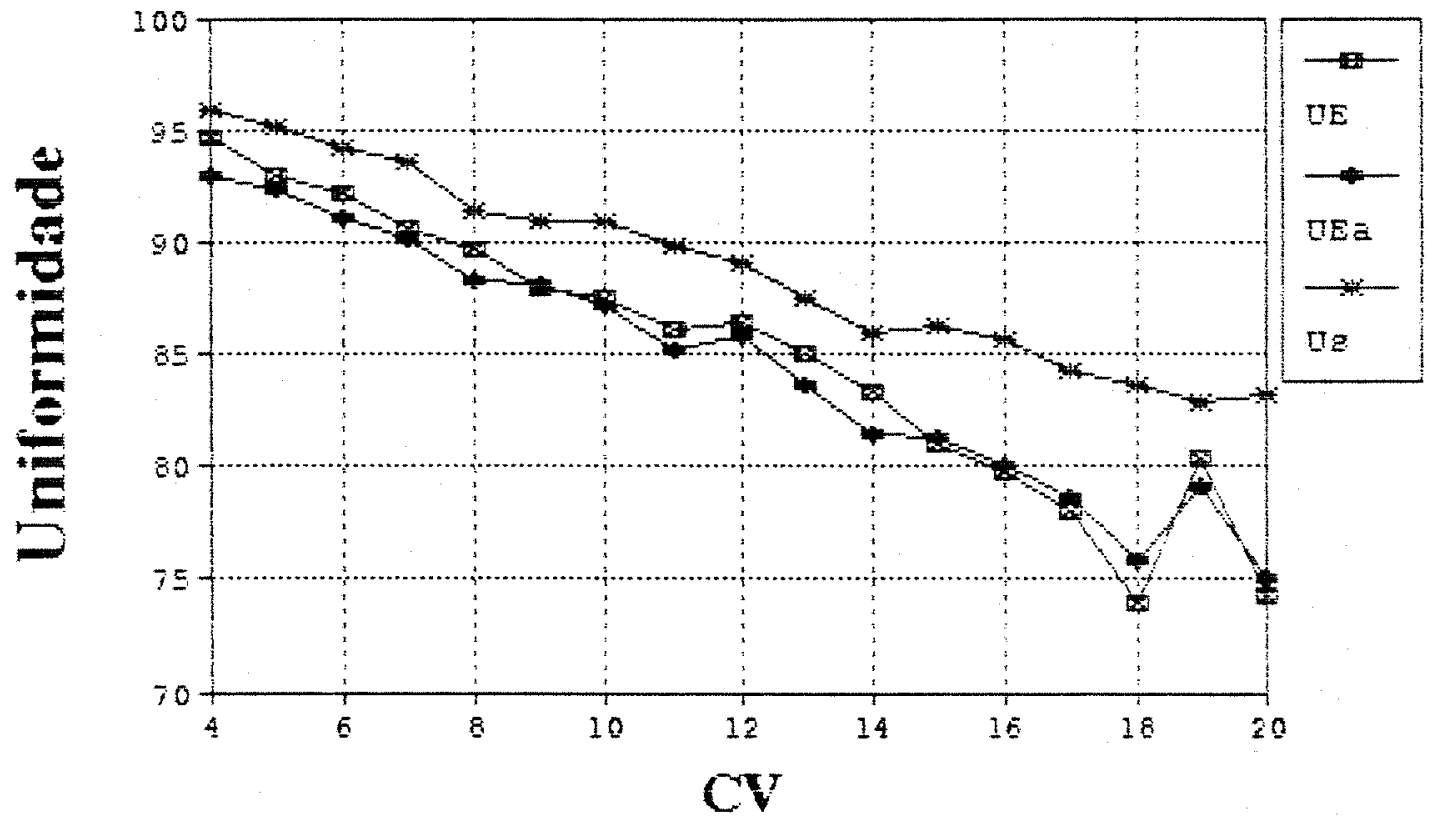

Figura 4 - Uniformidade $x$ CV para tamanho amostral de 48 emissores; emissor A. 


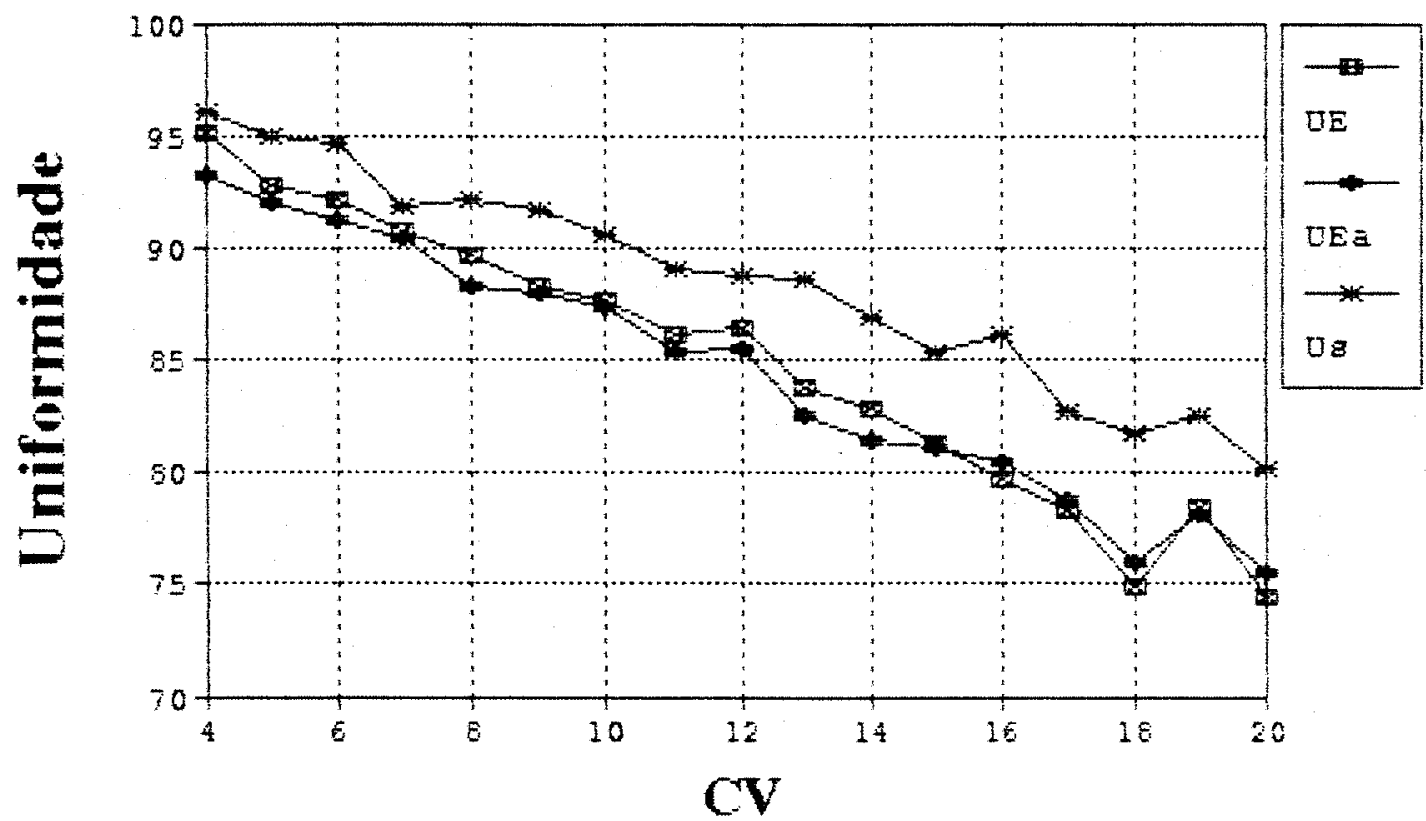

Figura 5 - Uniformidade $x$ CV para tamanho amostral de 64 e 66 emissores; emissor A.

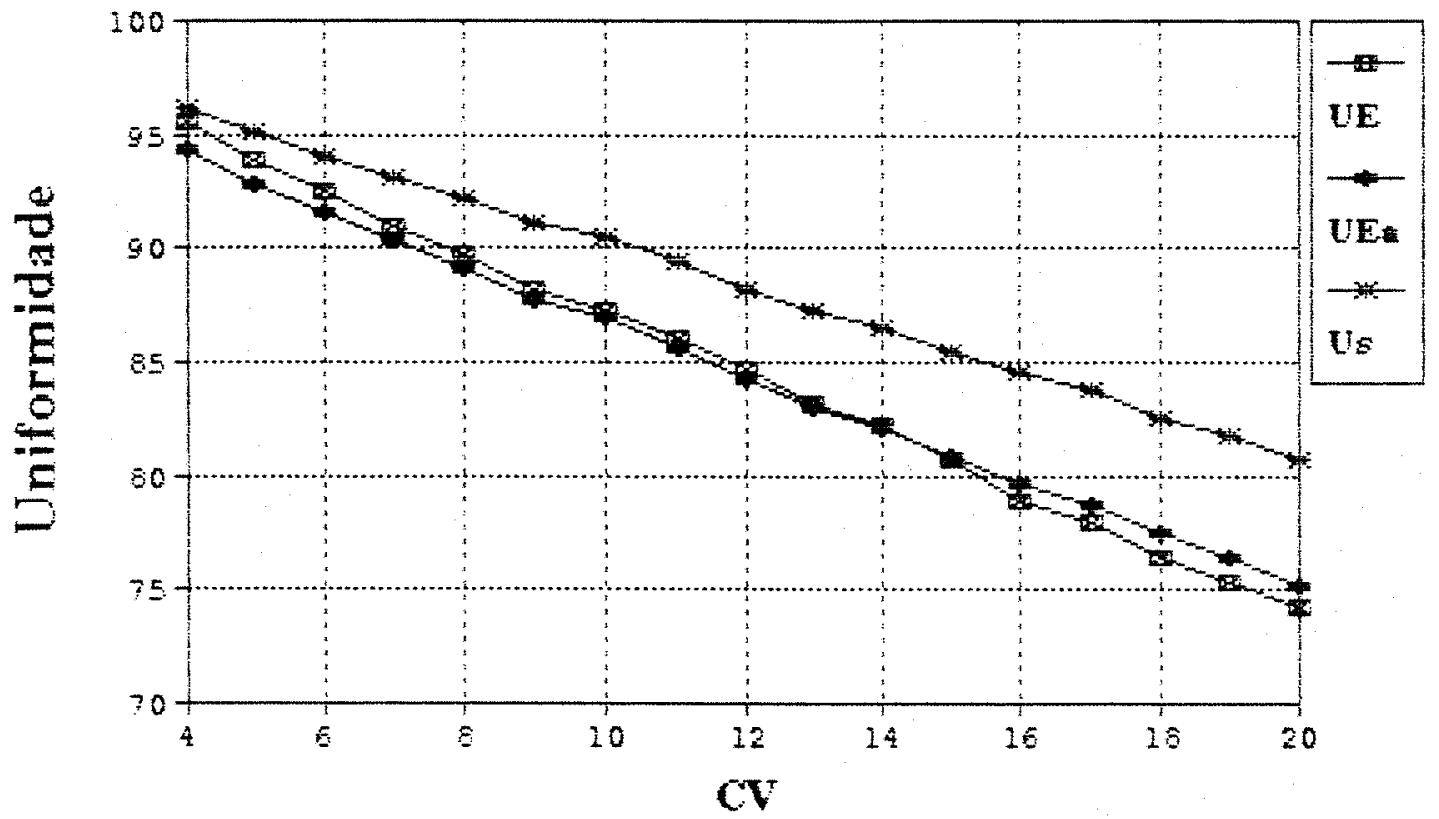

Figura 6 - Uniformidade $x$ CV para valores dos censos; emissor A. 


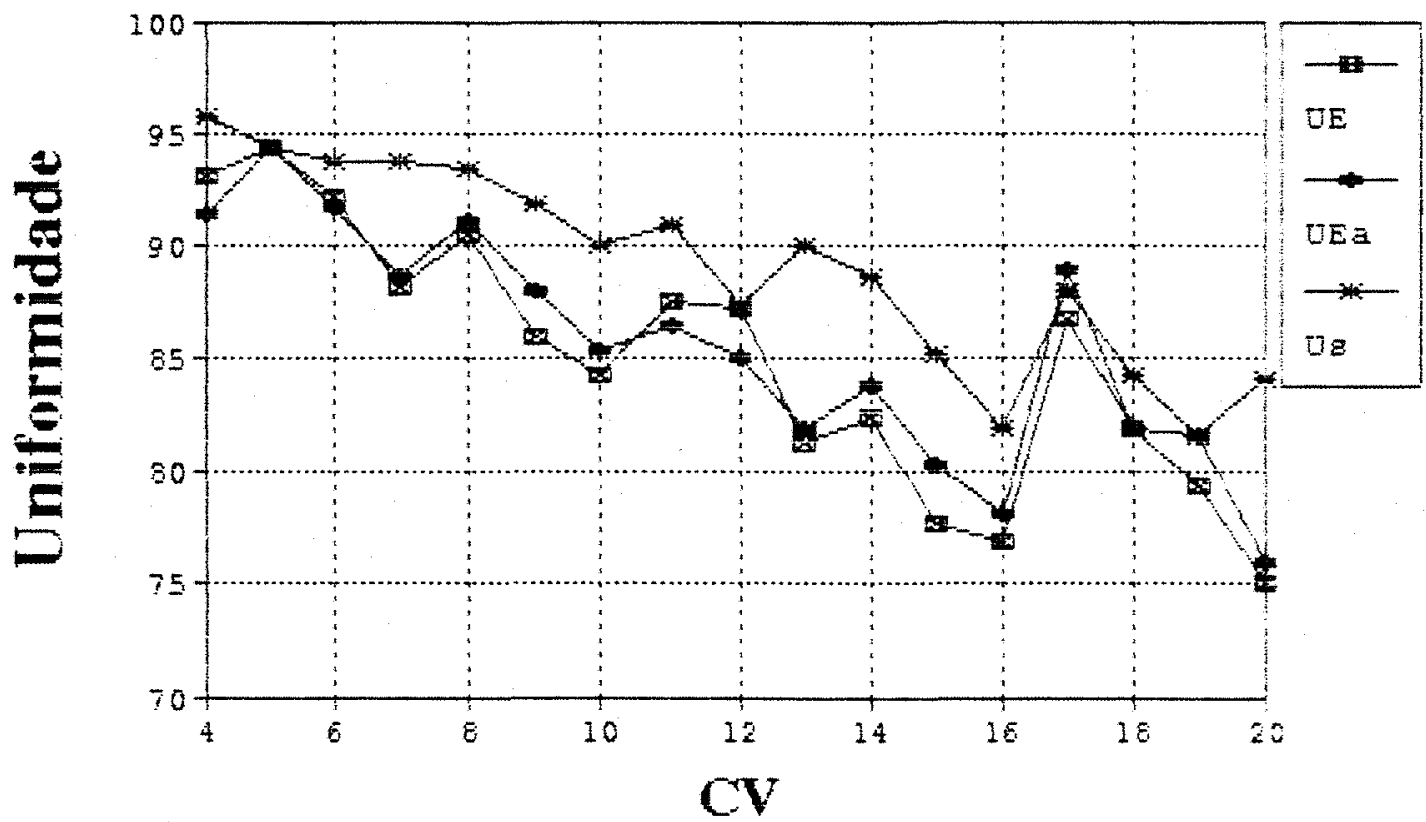

Figura 7 - Uniformidade $x$ CV para tamanho amostral de 12 emissores; emissor $B$.

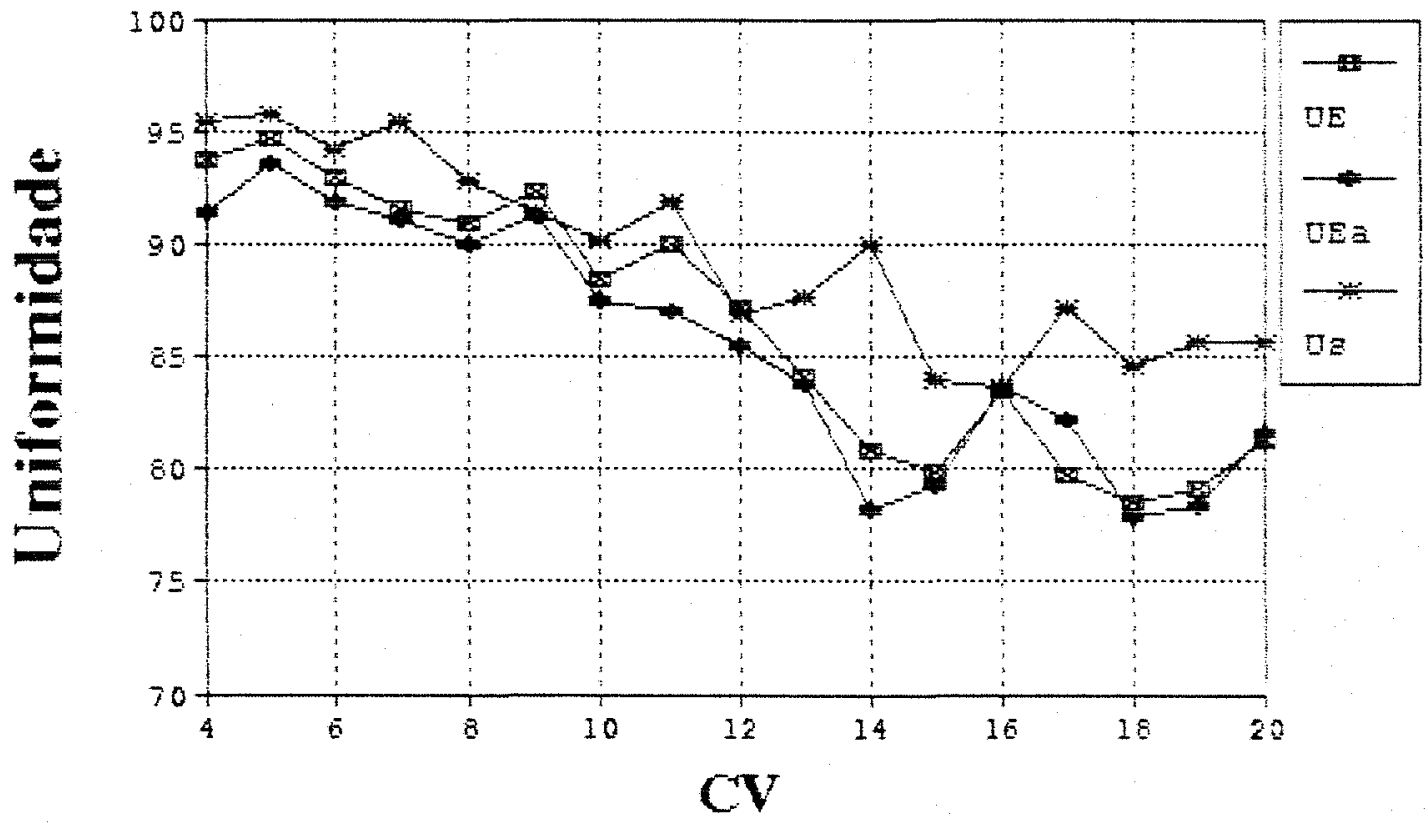

Figura 8 - Uniformidade $x$ CV para tamanho amostral de 18 emissores; emissor B. 


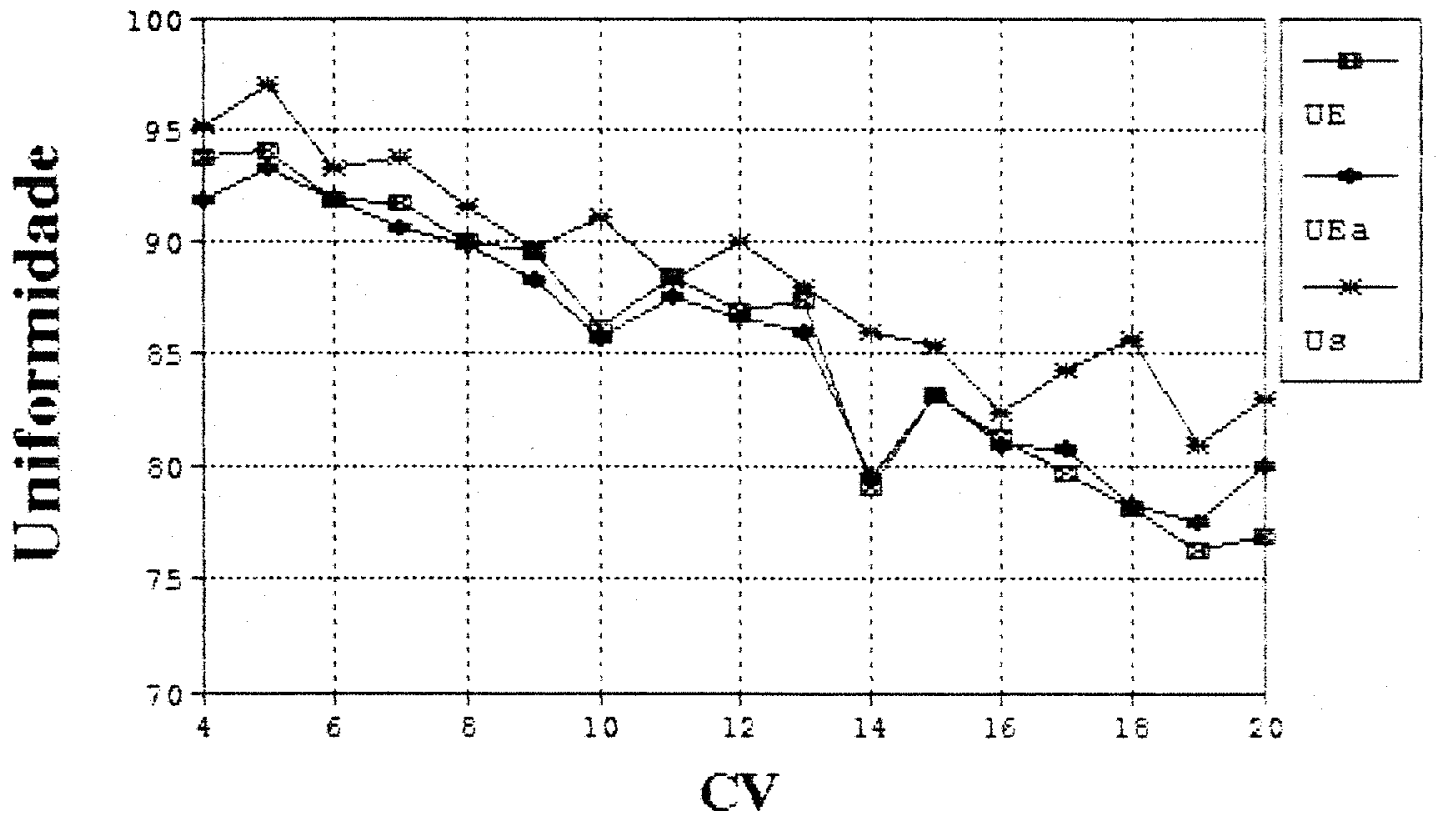

Figura 9 - Uniformidade $x$ CV para tamanho amostral de 24 emissores; emissor $B$.

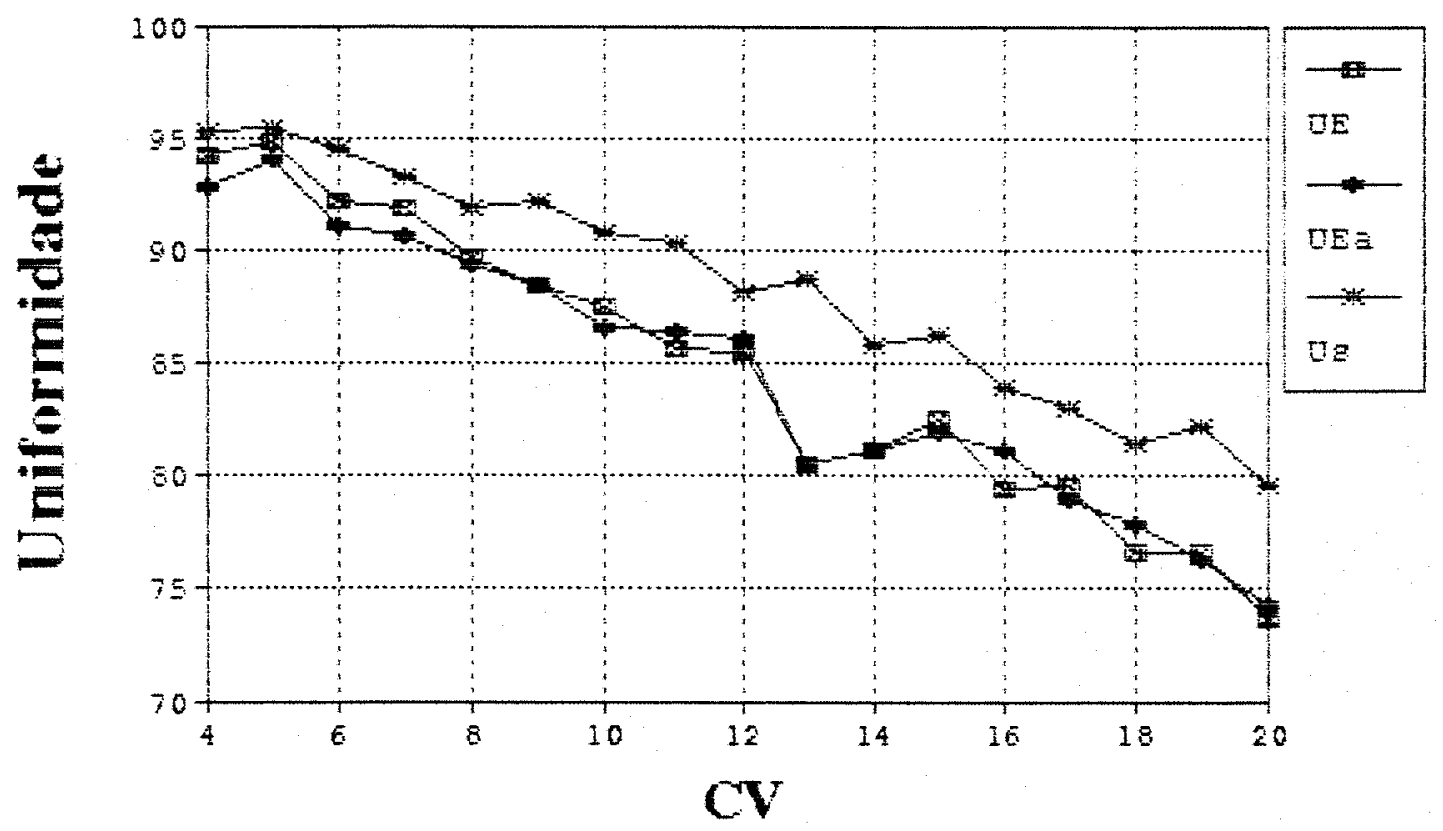

Figura 10 - Uniformidade $x$ CV para tamanho amostral de 48 emissores; emissor B. 


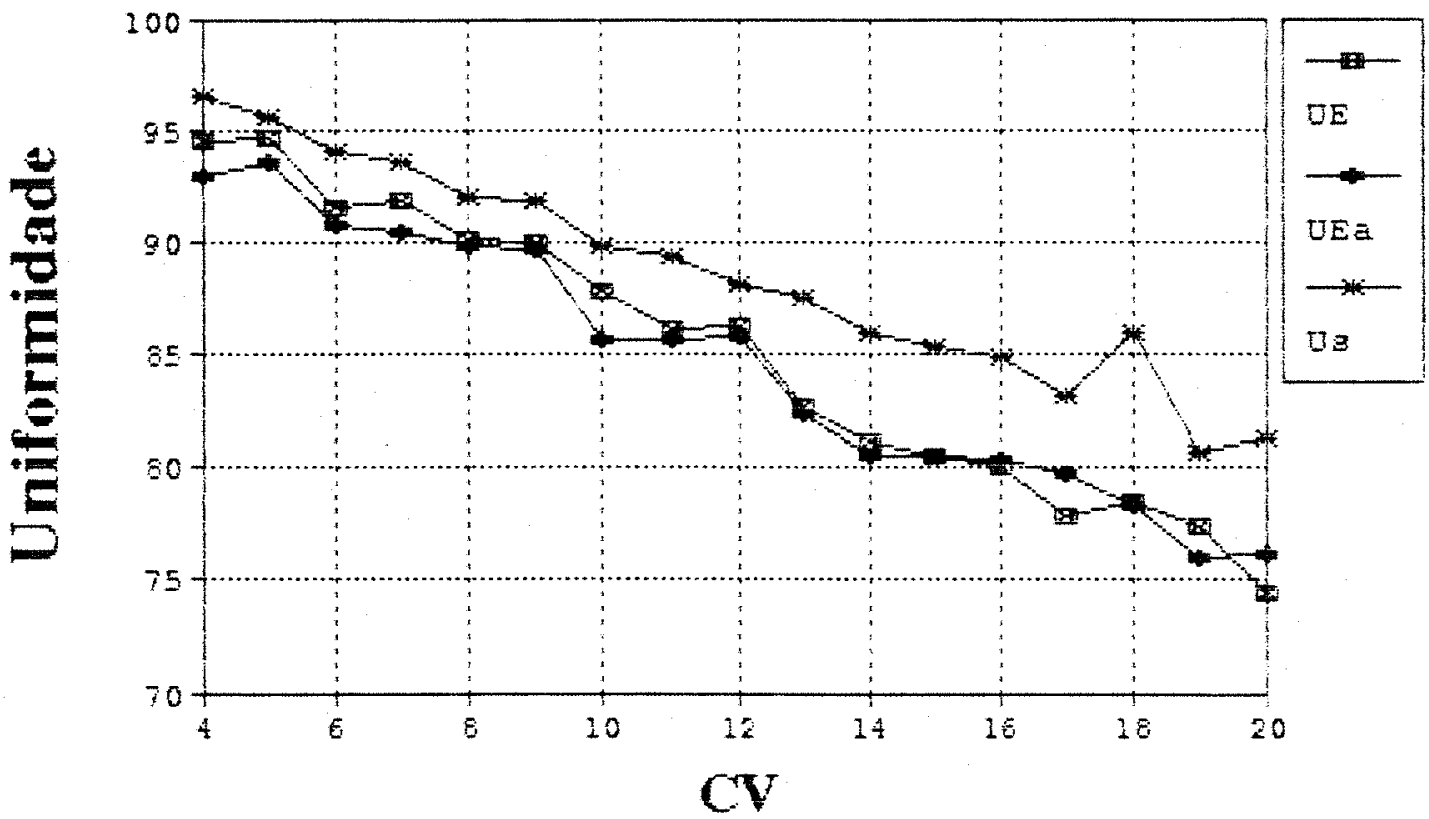

Figura 11 - Uniformidade $x$ CV para tamanho amostral de 64 e 66 emissores; emissor $B$.

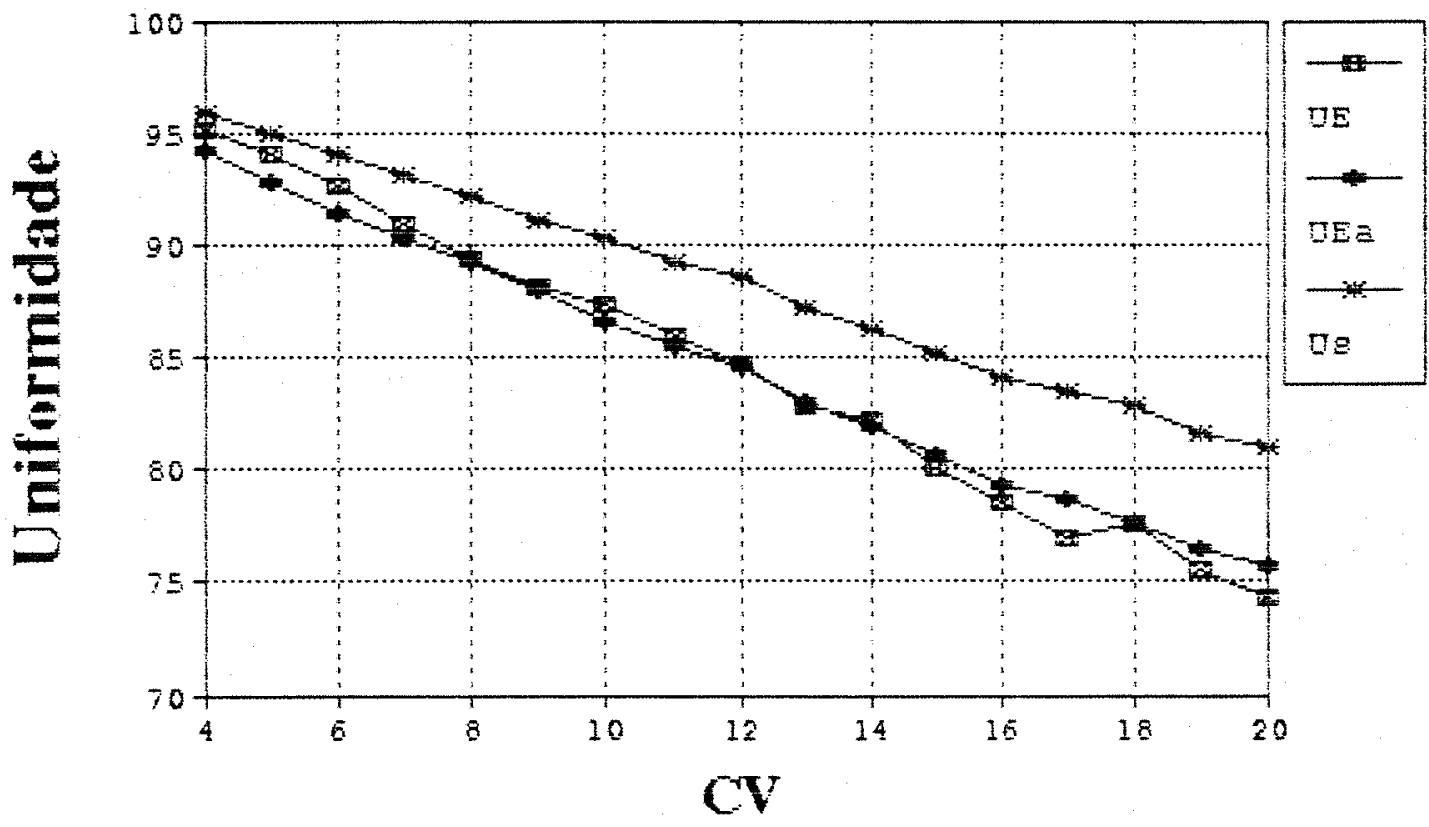

Figura 12 - Uniformidade $x$ GV para valores dos censos; emissor $B$. 


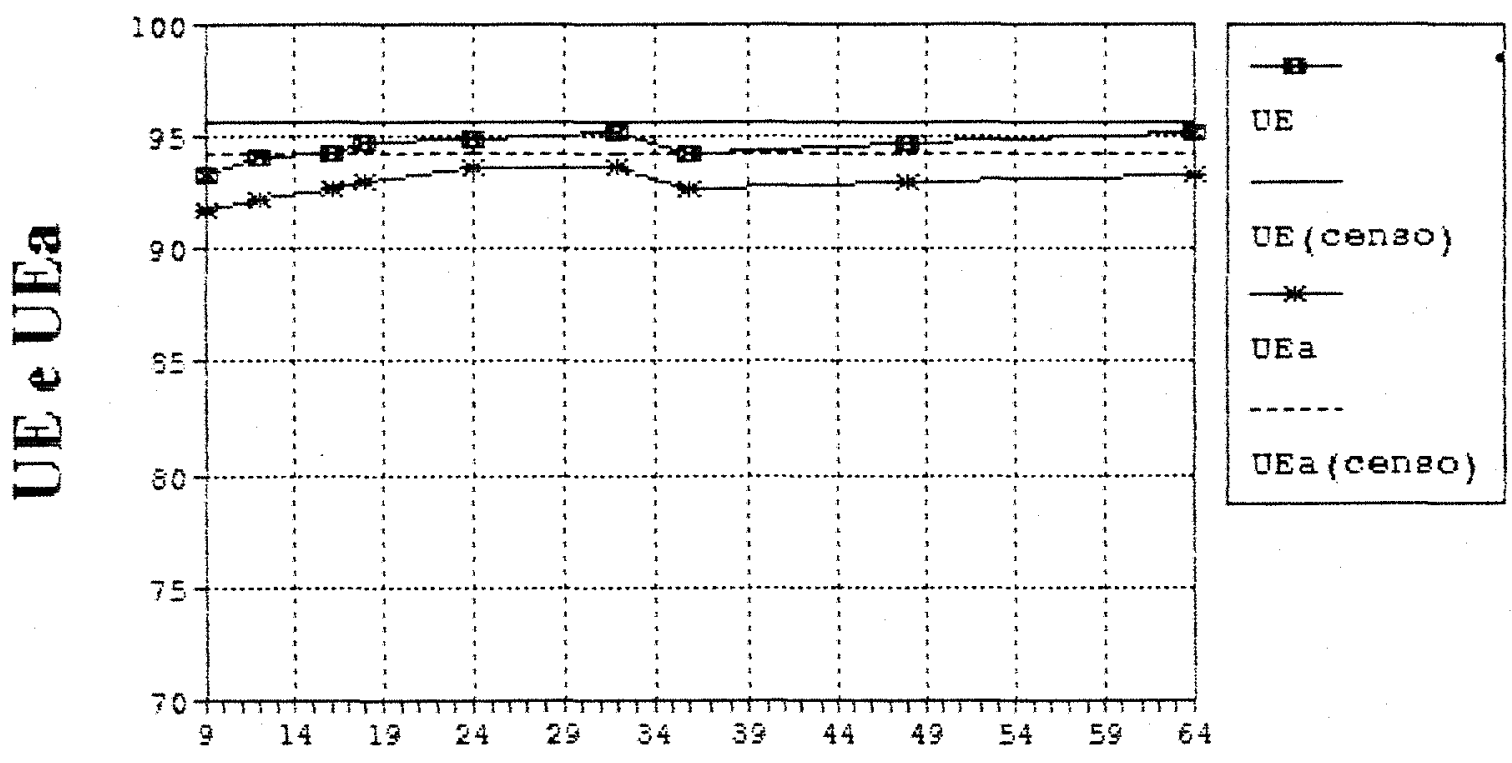

Numero de emissores por amostra

Figura 13 - Uniformidade de emissão (UE) e uniformidade de emissão absoluta (UE $\left.{ }_{a}\right) \times$ tamanho amostral. CV $=4 \%$; emissor A.

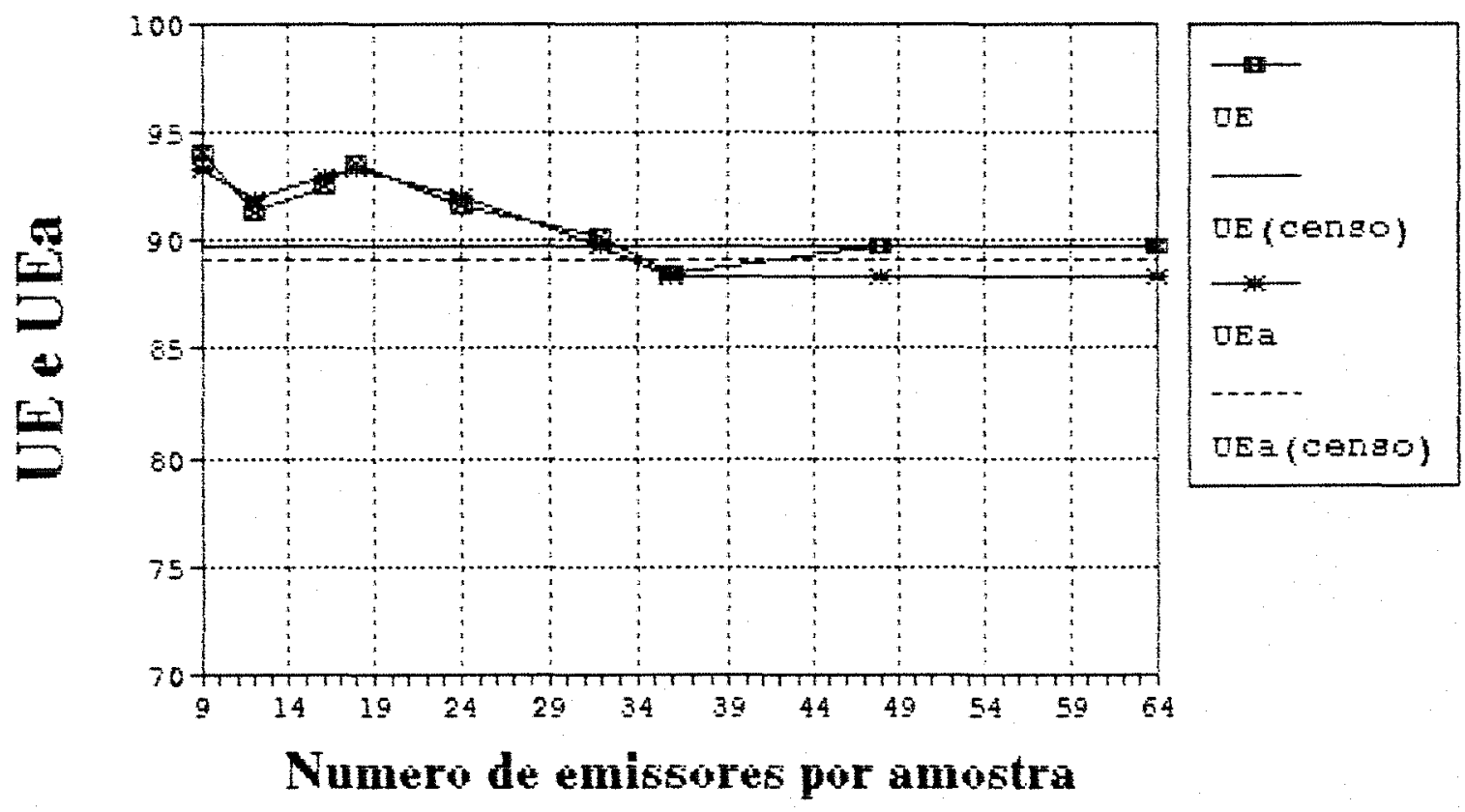

Figura 14 - Uniformidade de emissão (UE) e uniformidade de emissão absoluta (UE ${ }_{a}$ ) $\times$ tamanho amostral. $C V=8 \%$; emissor $A$. 


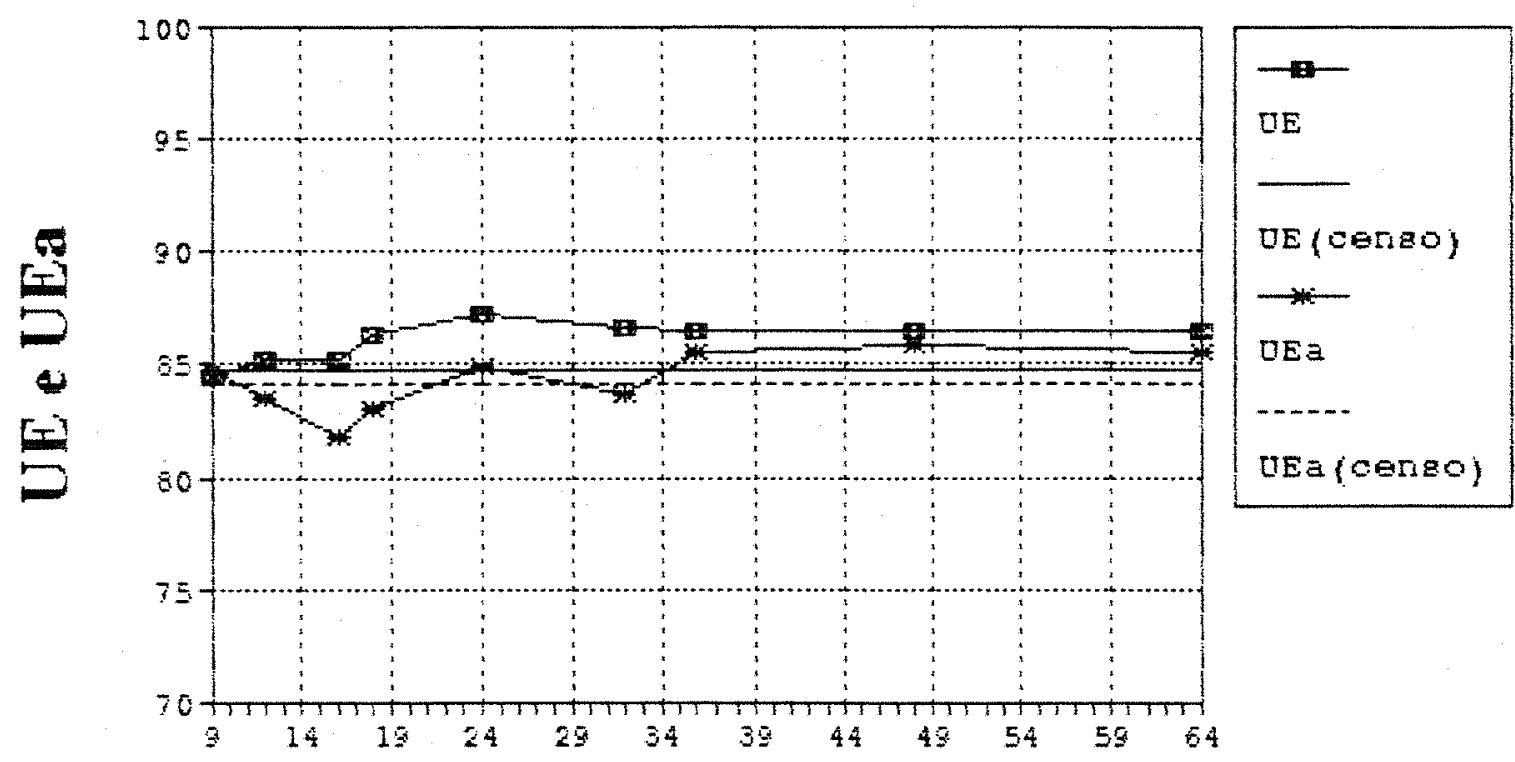

Numero de emissores por amostra

Figura 15 - Uniformidade de emissão (UE) e uniformidade de emissão absoluta $\left(U E_{a}\right) \times$ tamanho amostral.

$C V=12 \%$; emissor $A$.

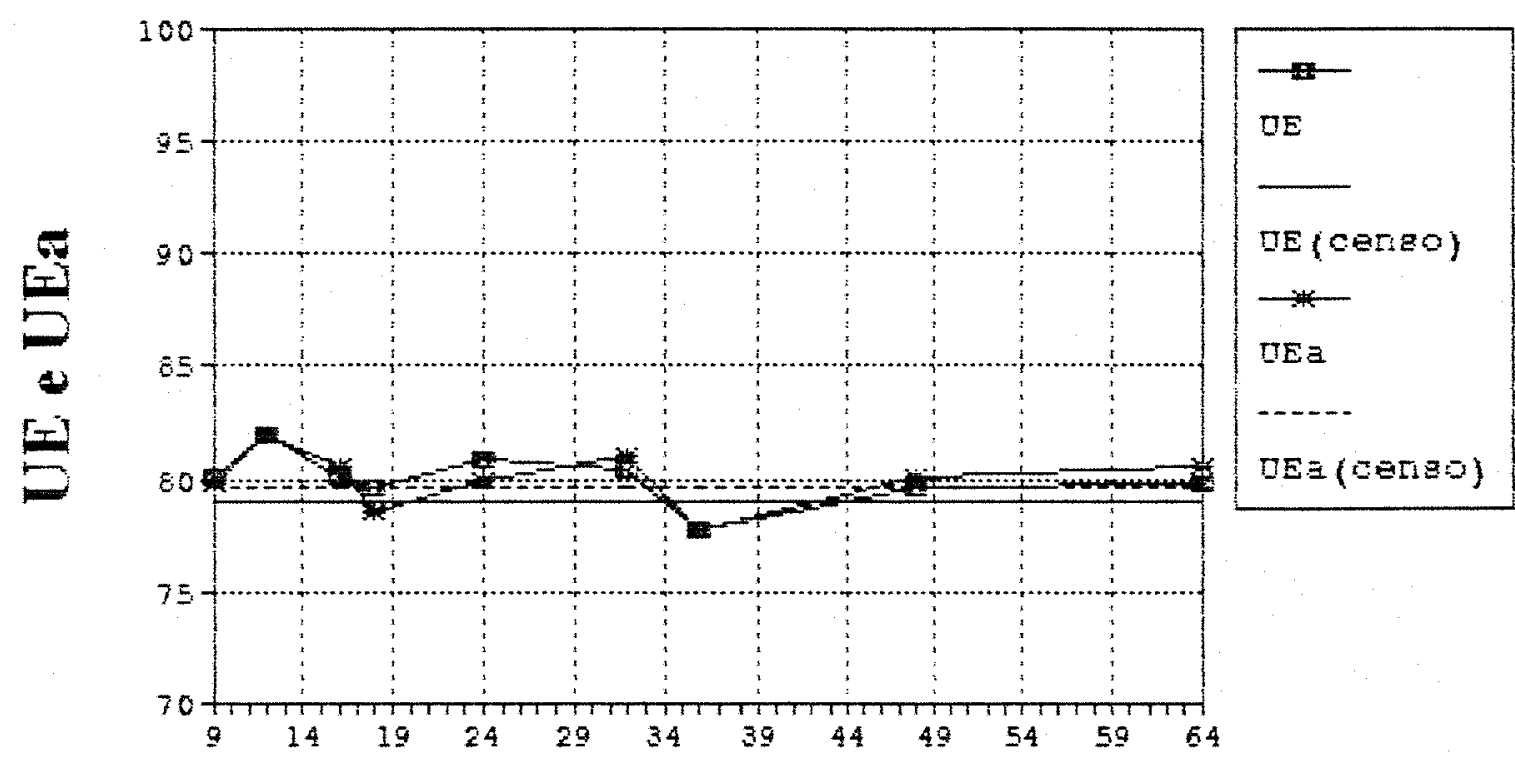

Numero de emissores por amostra

Figura 16 - Uniformidade de emissão (UE) e uniformidade de emissão absoluta (UE) $\times$ tamanho amostral.

CV $=16 \%$; emissor $A$. 


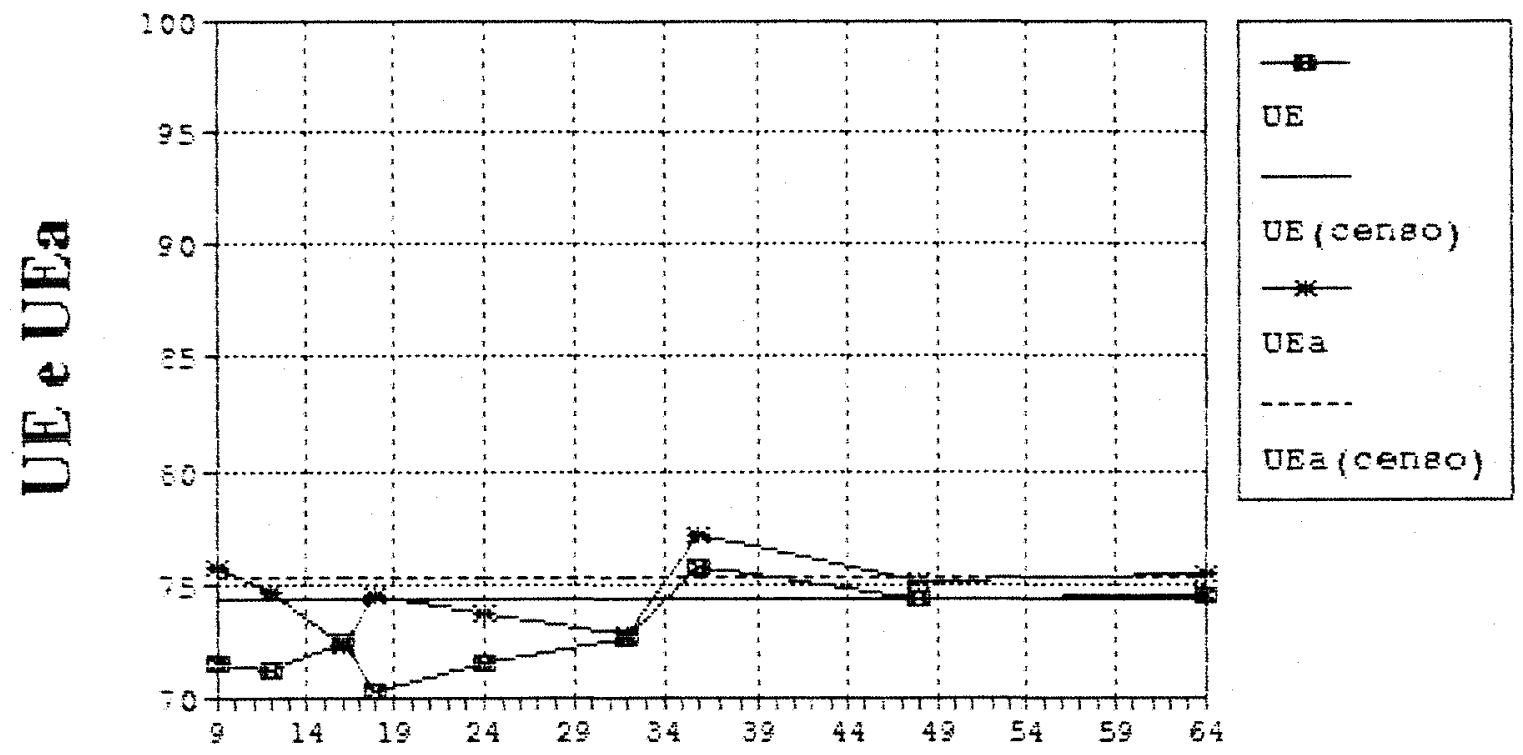

Numero de emissores por amostra

Figura 17 - Uniformidade de emissão (UE) e uniformidade de emissão absoluta (UE $) \times$ tamanho amostral.

CV $=20 \%$; emissor A.

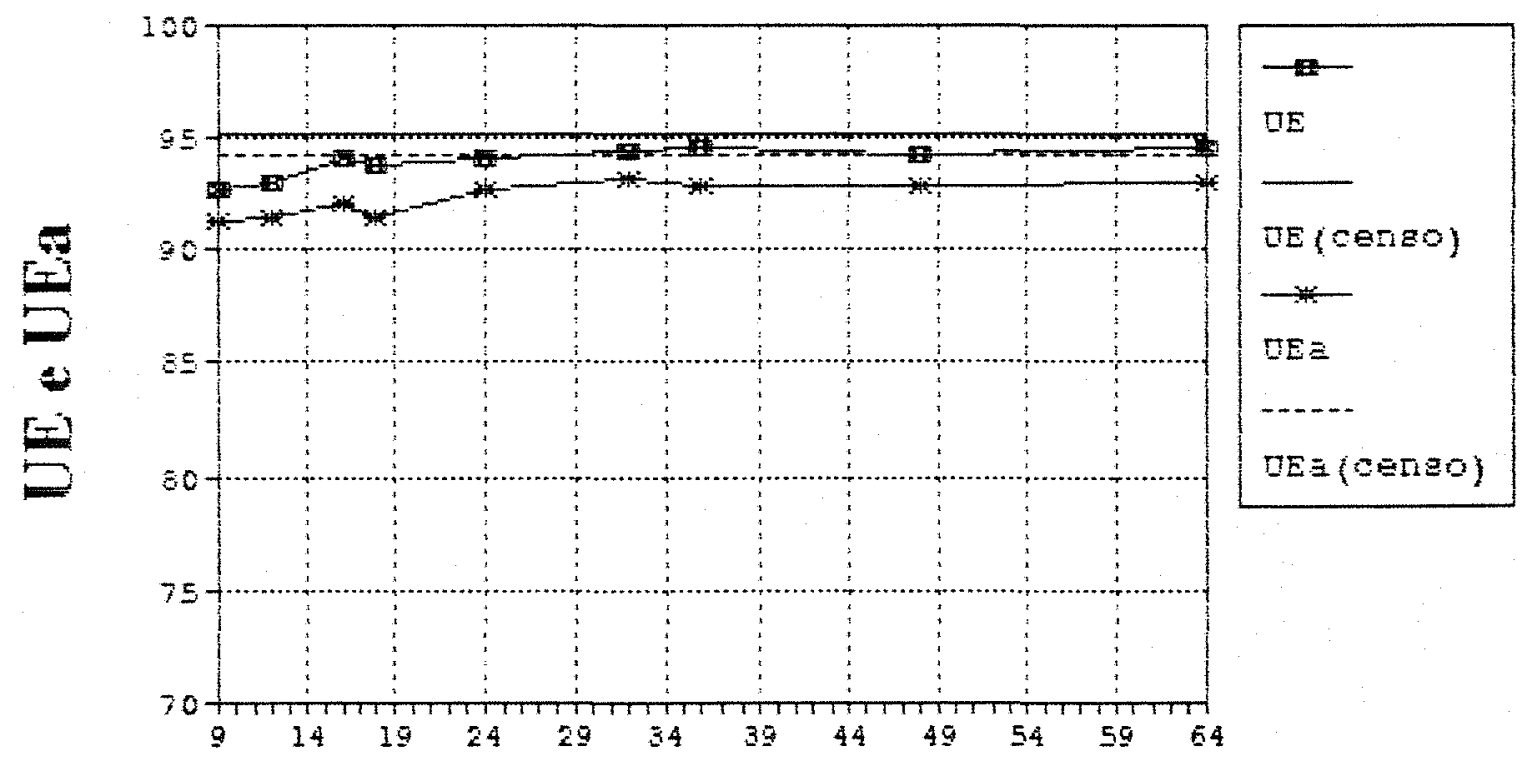

Numero de emissores por amostra

Figura 18 - Uniformidade de emissão (UE) e uniformidade de emissão absoluta (UE) $)$ tamanho amostral.

CV $=4 \%$; emissor $B$. 


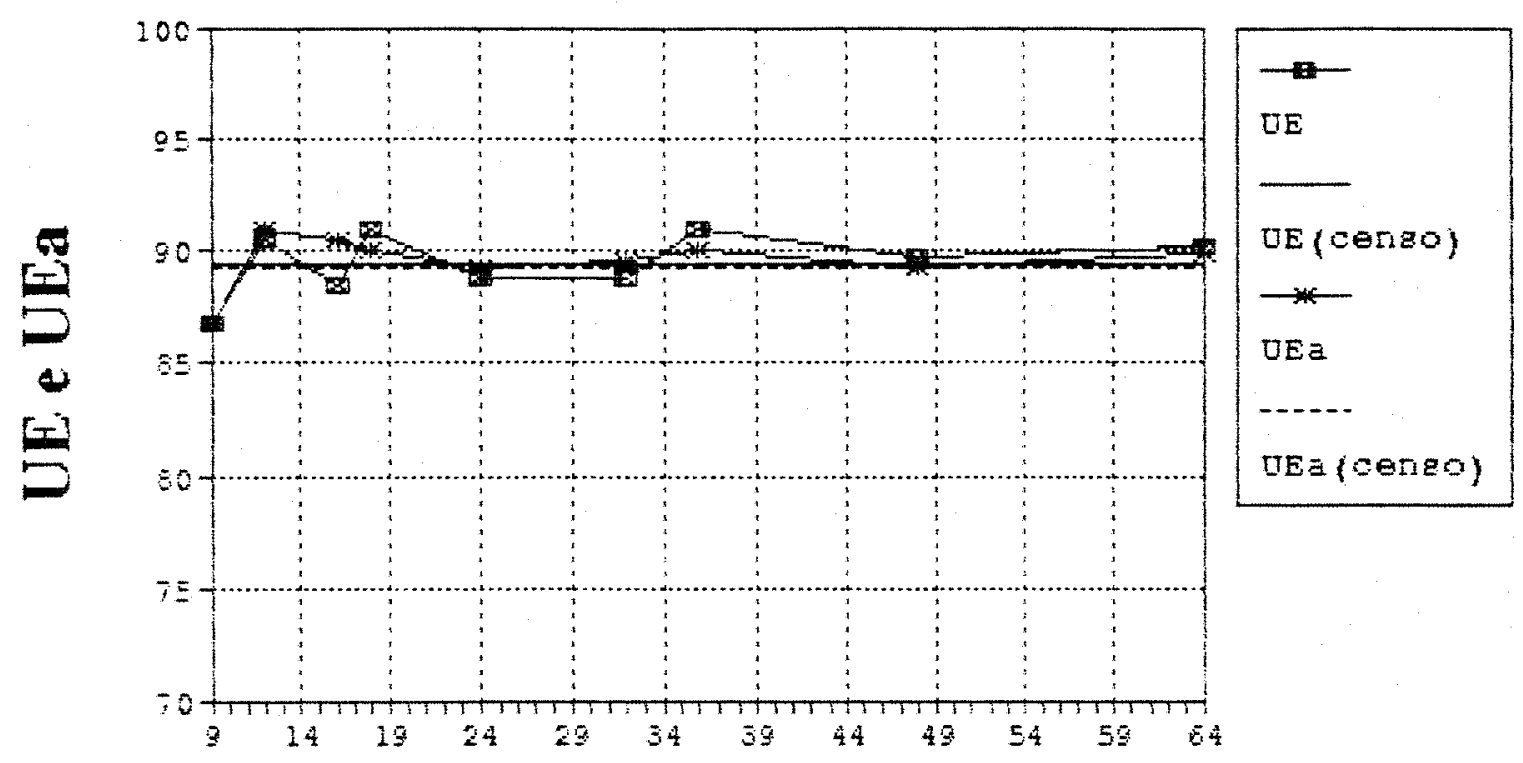

Numero de emissores por amostra

Figura 19 - Uniformidade de emissão (UE) e uniformidade de emissão absoluta $\left(U E_{a}\right) \times$ tamanho amostral. $C V=8 \%$; emissor $B$.

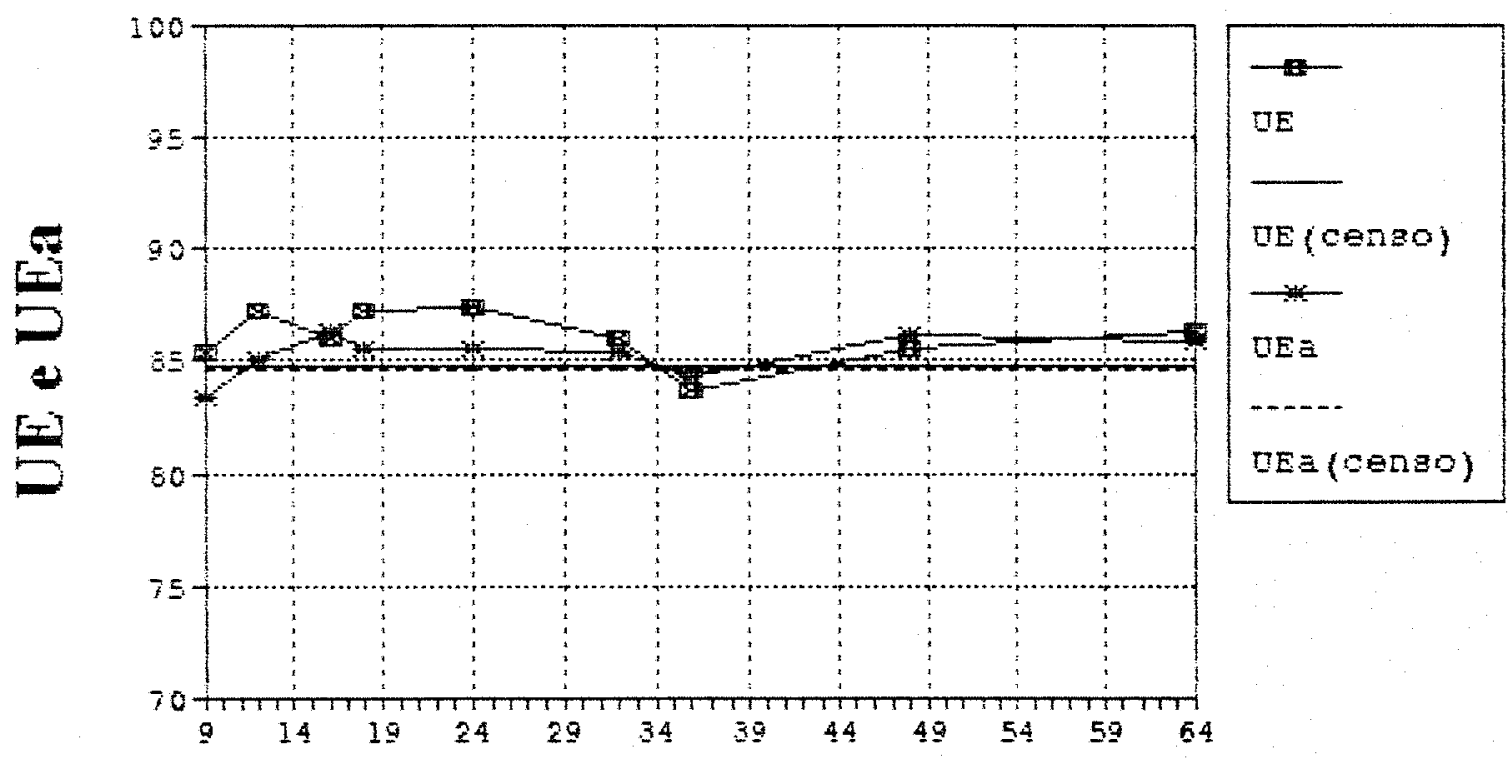

Numeró de emissores por amostra

Figura 20 - Uniformidade de emissão (UE) e uniformidade de emissão absoluta $\left(U E_{a}\right) \times$ tamanho amostral. $C V=12 \%$; emissor $B$. 


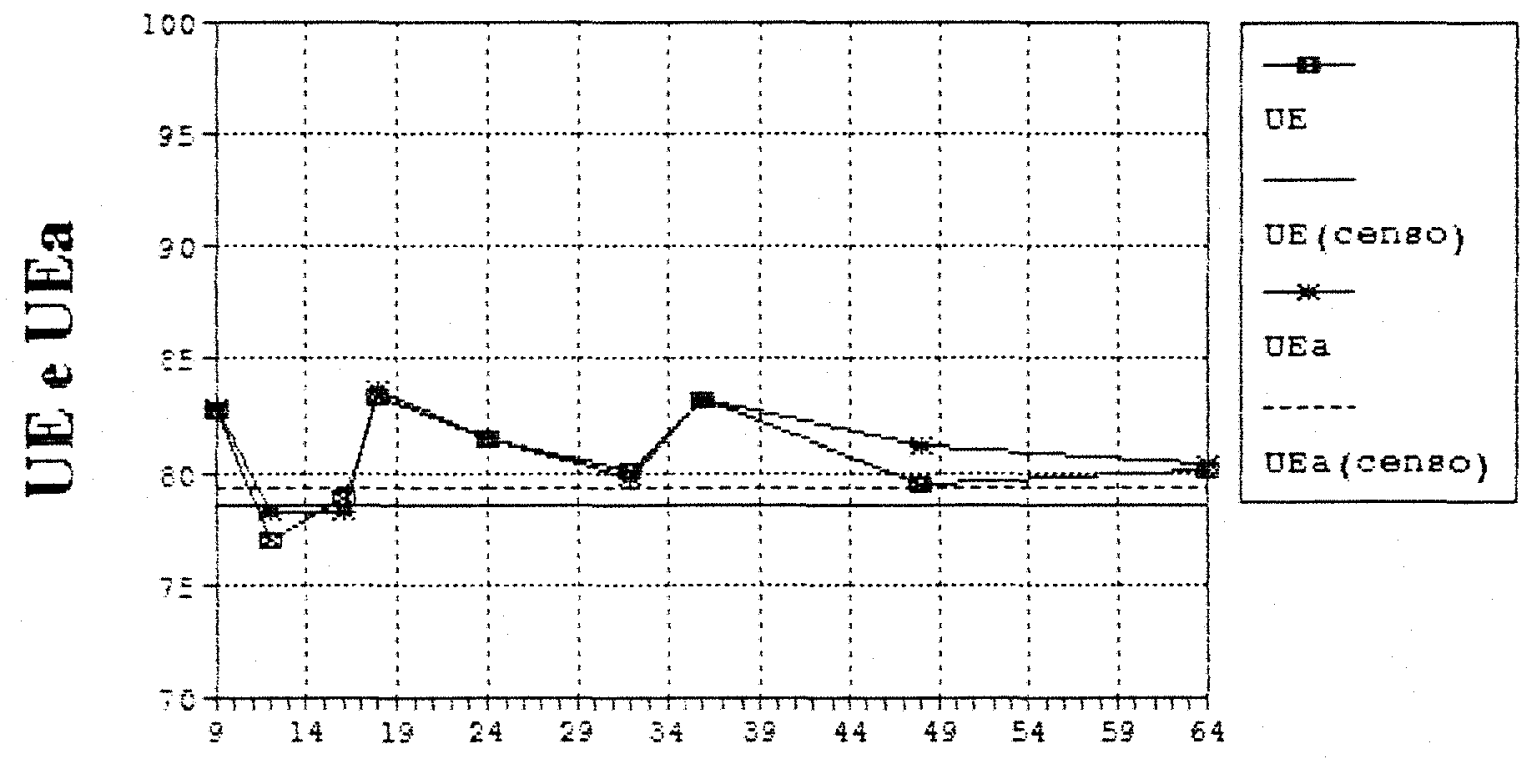

Numero de emissores por amostra

Figura 21 - Uniformidade de emissão (UE) e uniformidade de emissão absoluta (UE $a^{\prime} \times$ tamanho amostral.

CV $=16 \%$; emissor $B$.

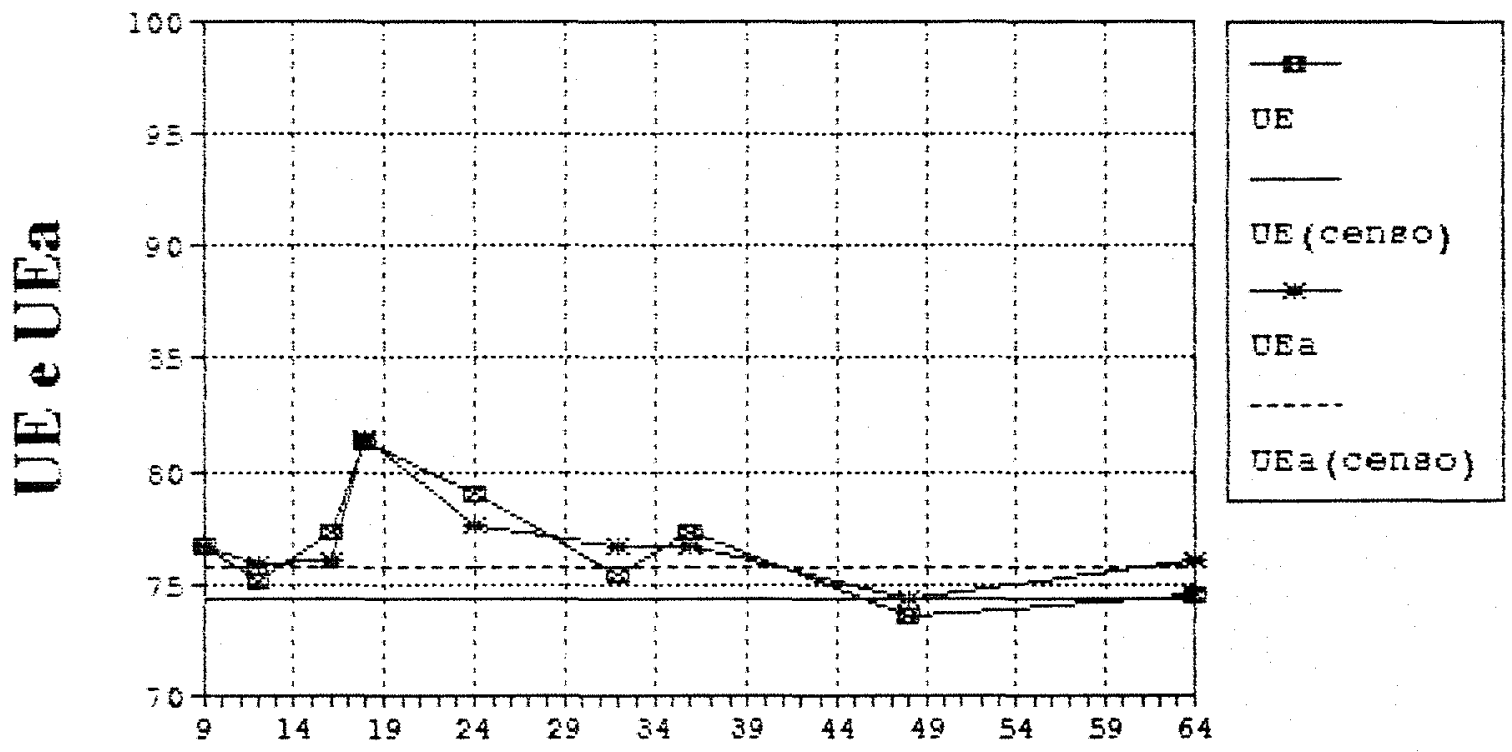

Numero de emissores por amostra

Figura 22 - Uniformidade de emissão (UE) e uniformidade de emissão absoluta $\left(U E_{a}\right) \times$ tamanho amostral.

CV $=20 \%$; emissor B. 


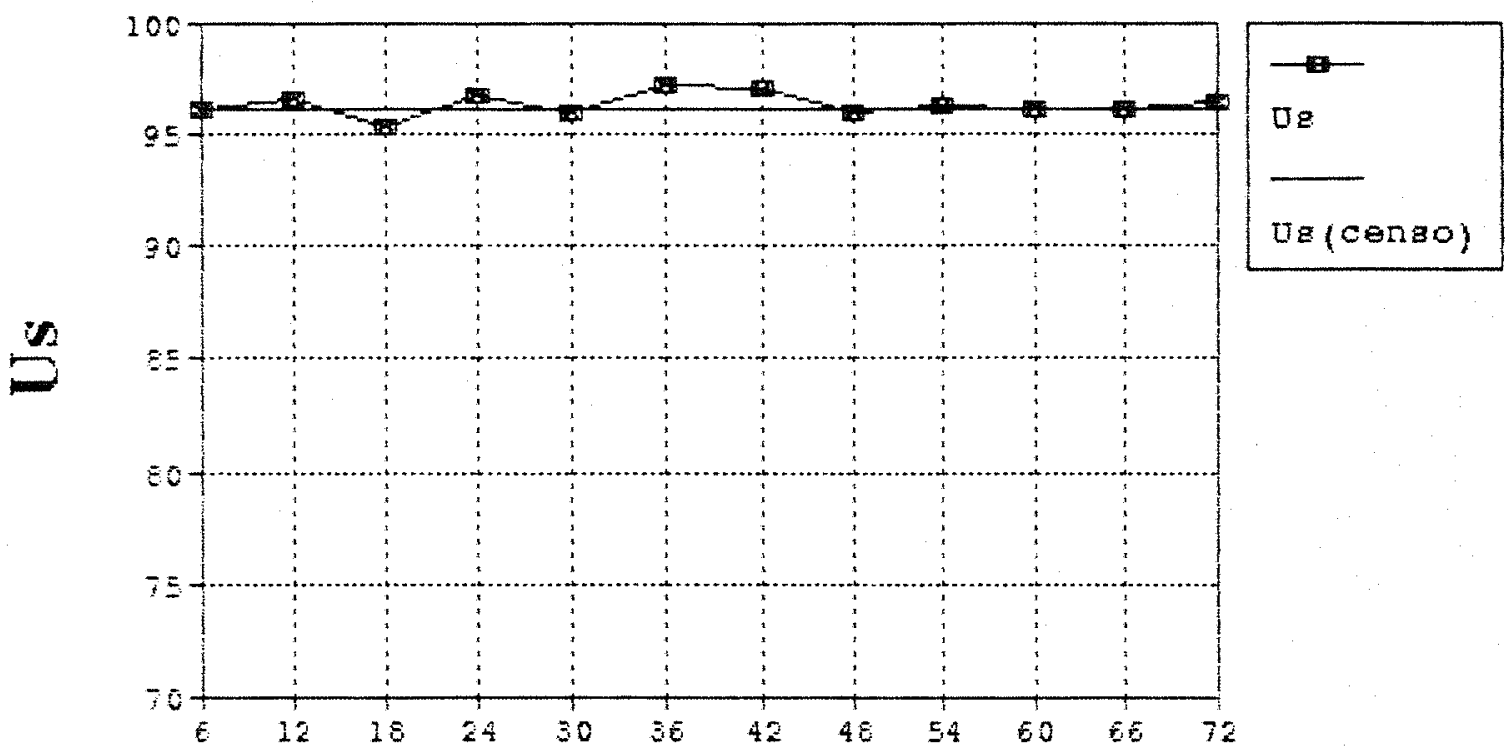

Numero de emissores por amostra

Figura 23 - Uniformidade estatística $\left(U_{s}\right) \times$ tamanho amostral. $\mathrm{CV}=4 \%$; emissor $\mathrm{A}$.

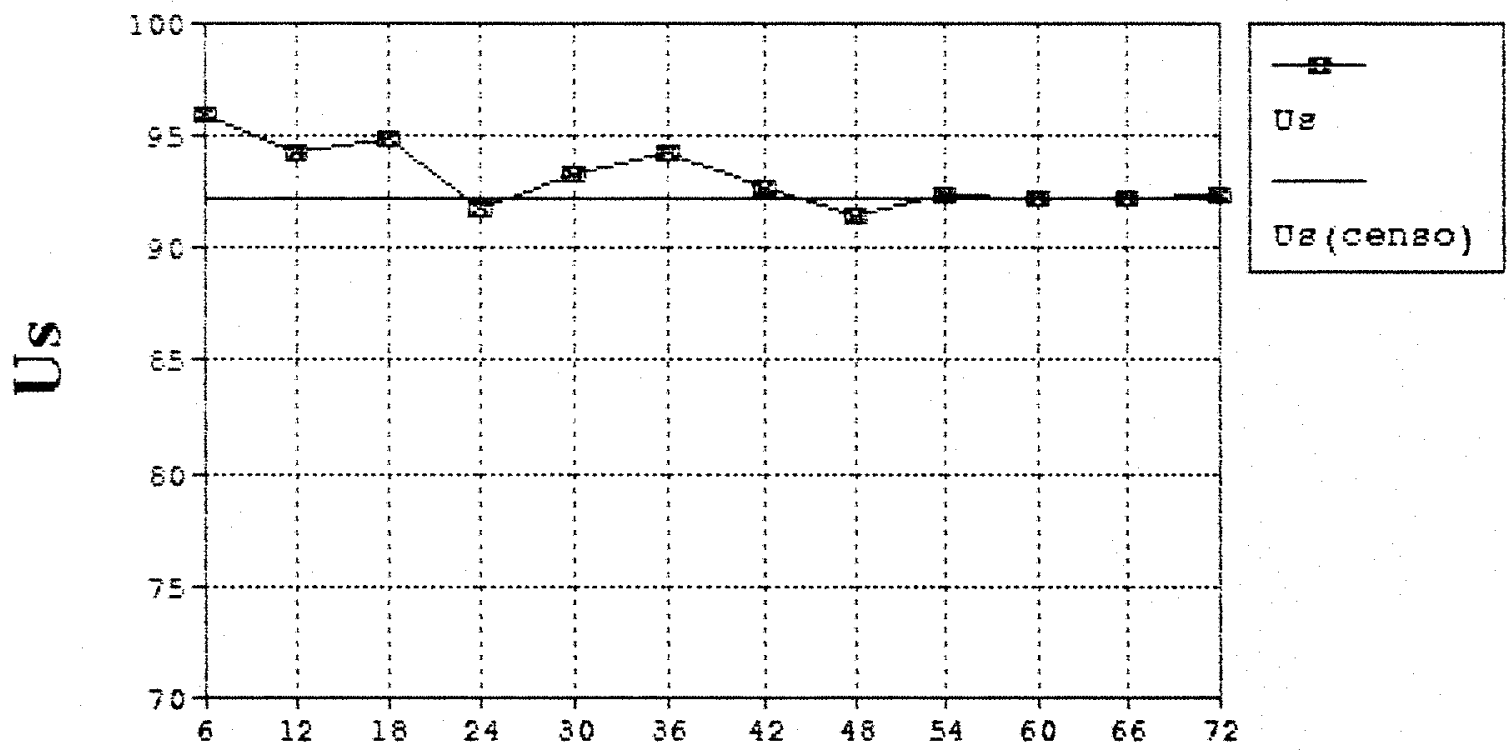

Numero de emissores por amostra

Figura 24 - Uniformidade estatistica $\left(U_{s}\right) \times$ tamanho amostral. $\mathrm{CV}=8 \%$; emissor $A$. 


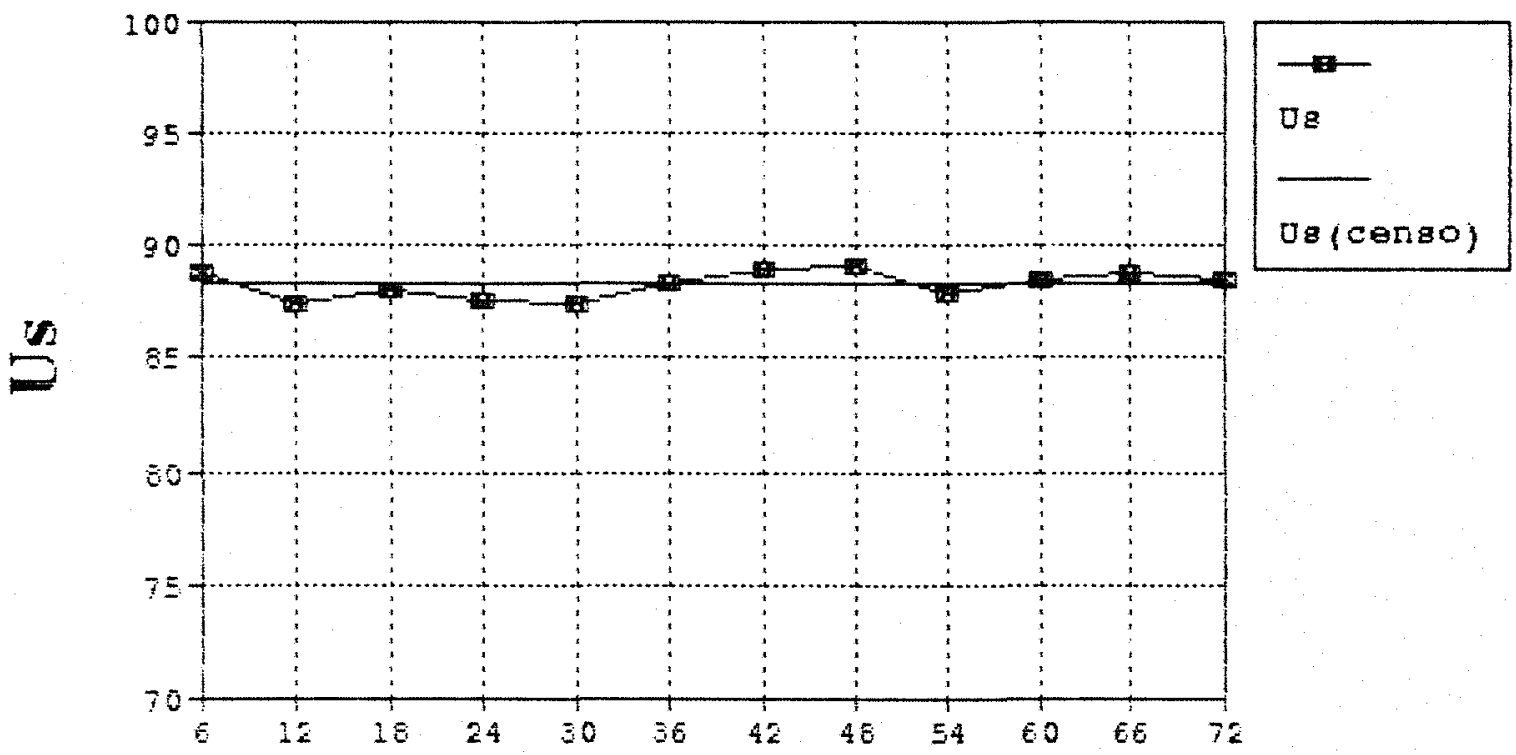

Numero de emissores por amostra

Figura 25 - Uniformidade estatistica $\left(U_{s}\right) x$ tamanho amostral. $\mathrm{CV}=12 \%$; emissor $\mathrm{A}$.

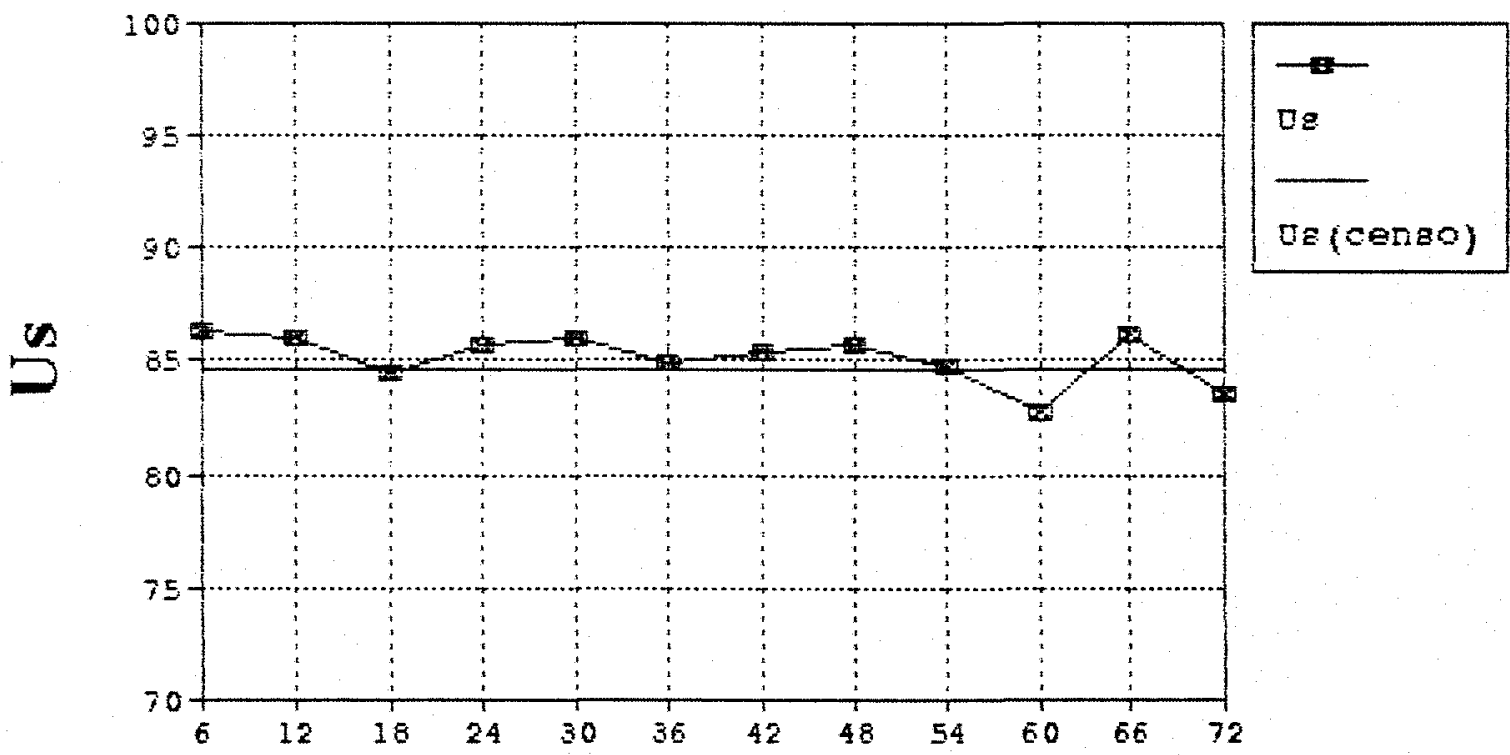

Numero de emissores por amostra

Figura 26 - Uniformidade estatística $\left(U_{0}\right) \times$ tamanho amostral. CV = 16\%; emissor A. 


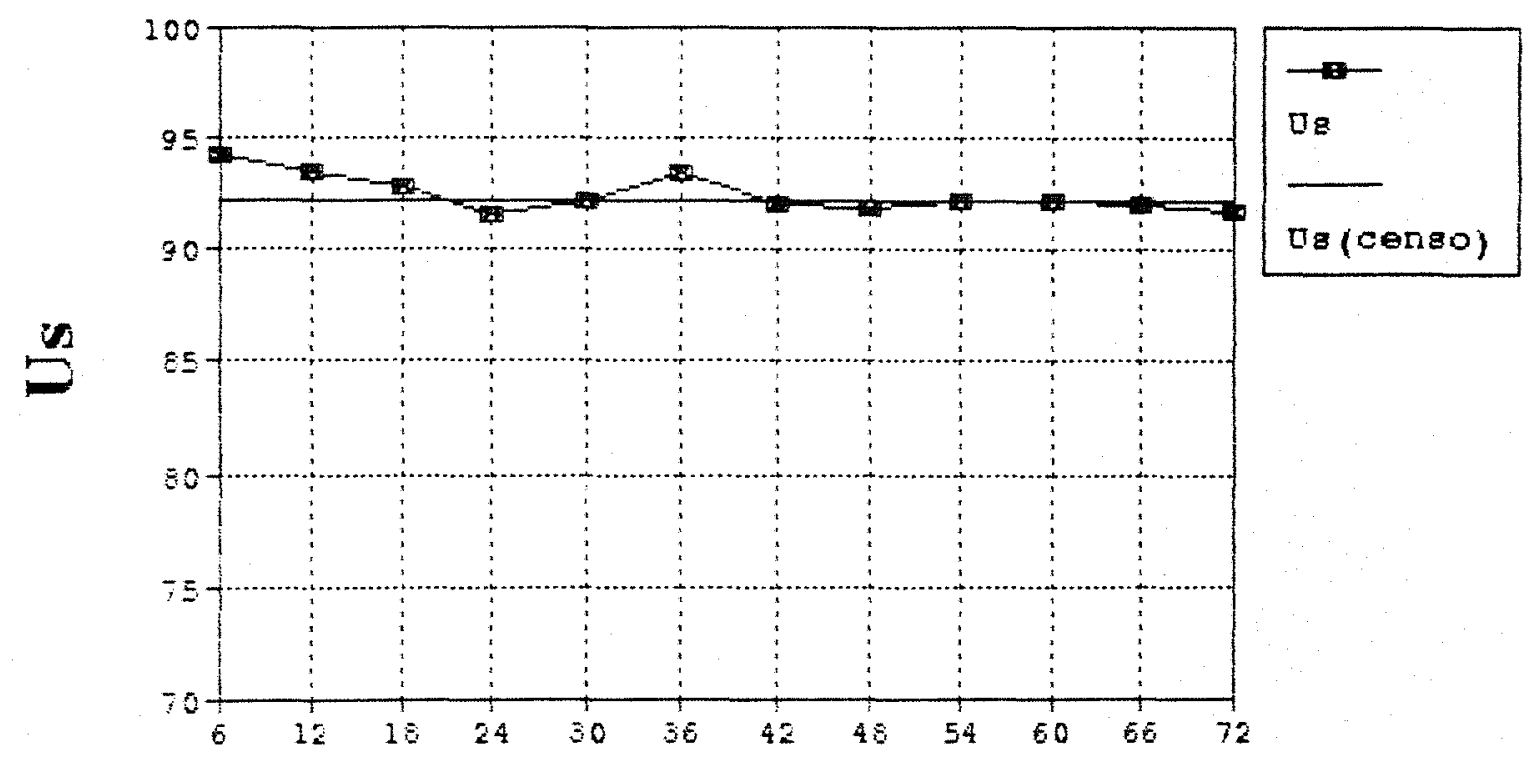

Numero de emissores por amostra

Figura 29 - Uniformidade estatistica $\left(U_{s}\right) \times$ tamanho amostral. $\mathrm{CV}=8 \%$; emissor $\mathrm{B}$.

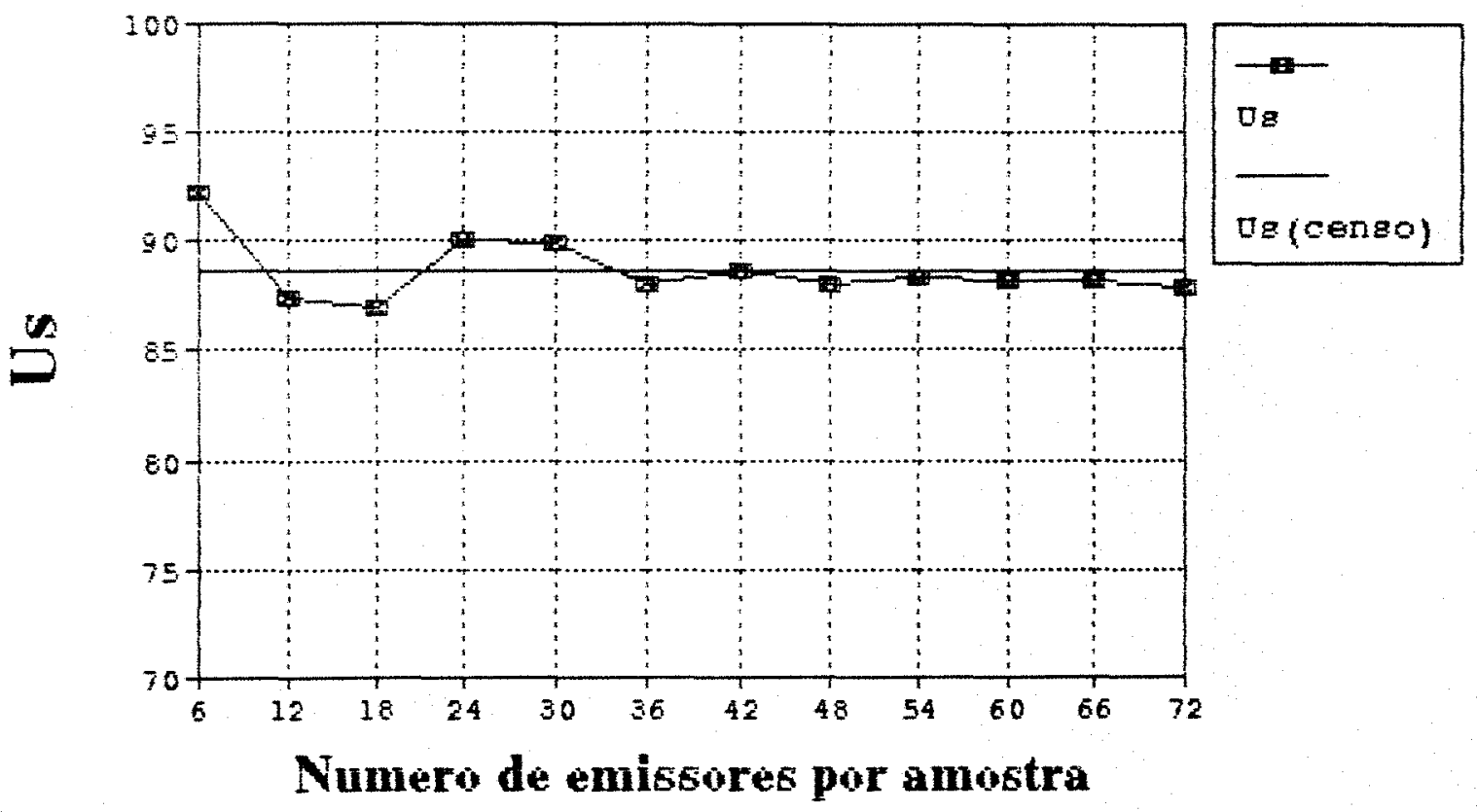

Figura 30 - Uniformidade estatistica $\left\langle U_{s}\right\rangle$ x tamanho amostral. $C V=12 \%$; emissor $B$. 

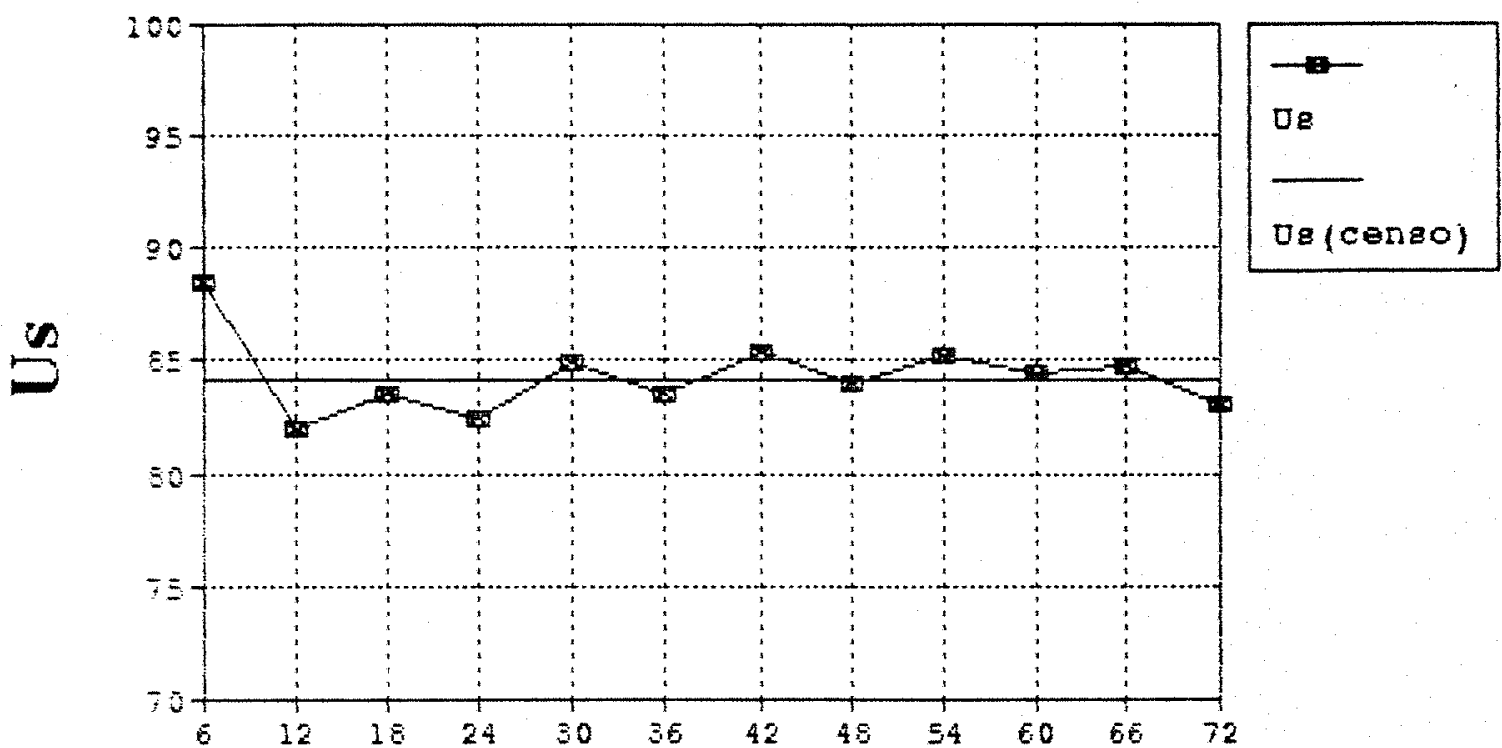

Numero de emissores por amostra

Figura 31 - Uniformidade estatística $\left(U_{s}\right) \times$ tamanho amostral. $\mathrm{CV}=16 \%$; emissor $B$.

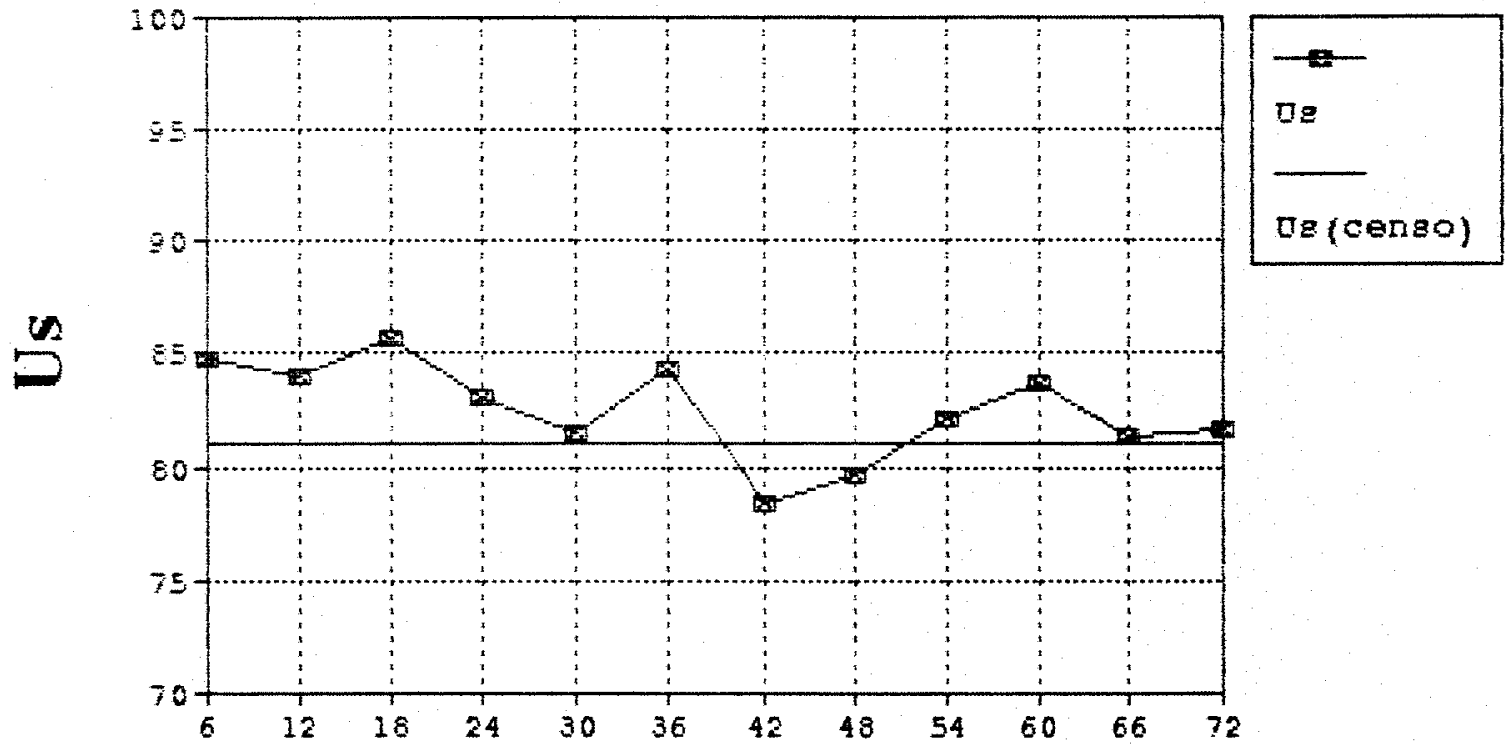

Numero de emissores por amostra

Figura 32 - Uniformidade estatística $\left(U_{,}\right\rangle \times$tamanho amostral. CV $=20 \%$; emissor $B$. 


\section{CONCLUSÕES}

Com base nos resultados obtidos e nas condiçres da metodologia aplicada, chegou-se ds seguintes concluszes:

- O coeficiente de uniformidade estatistica (U) mostrou-se - mais vantajoso dos trés metodos avaliados, devido a sua capacidade superior de estimar os valores de uniformidade.

- E possivel estimar-se o valor de uniformidade por quais-

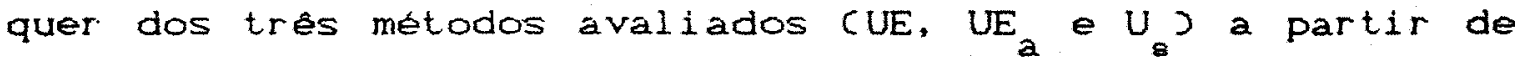
um valor previamente conhecido de um outro desses mesmos metodos.

Sugere-se para outros trabalhos a avaliação da suficiéncia do tamanho amostral em cada um dos mesmos metodos aqui avaliados, em funçăo do número de emissores da área avaliáda. 
REFERENCI AS BIBLI OGRAFICAS

AMERICAN SOCIETY OF AGRICULTURAL ENGINEERS. DEsign, installation and performance of trickle irrigation systems. In: ASAE standards 1985. St. Joseph. 1985. p. 216-40. (ASAE. EP, 405).

BENAMI, A. \& OFEN, A. Irrigation engineering. Haifa, Irrigation Engineering Scietific Publications, 1984. 257p.

BERNUTH, R.D. von \& SOLOMON, K.H. Design principles. In: NAKAYAMA. F.S. \& BUCKS, D. A. ed. Trickle irrigation for crop production. Amsterdam. Elsevier, 1986 . cap.Z, p.27141. (Development in Agricultural Engineering, 9 ).

BOTREL. I.A. Hidráulica de microaspersores e de 1 inhas laterais para irrigaçã localizada. Piracicaba, 1984. 78p. CMestrado - Escola Superior de Agricultura "Luiz de Queiroz" USPJ.

BRALTS, V.F. Field performance and evaluation. In: NAKAYAMA, F.S. \& BUCKS, D.A. ed. Trickle irrigation for crop production. Amsterdam. Elsevier, 1986. p.216-40. CDevelopment in Agricultural Engineering, 93.

BRALTS, V.F. \& KESNER, C.D. Drip irrigation field uniformity estimation. Transactions of the ASAE, St. Joseph, 26: $1369-74,1983$.

BRALTS, V.F.; EDHARD, D.M.; WU, I.P. Drip irrigation design and evaluation based on statistical uniformity concept. In: HILLEL, D. ed. Advances in irrigation. Orlando, Academic Press, 1987 . v. 4, P. 67-117.

BRALTS, V.F.; WU, I.P.; GITLIN, H.M. Drip irrigation uniformity considering emitter plugging. Transactions of the $A S A E$. St. Joseph, 24(5): 1234-40, $1981 \mathrm{a}$.

BRALTS, V.F.; WU, I.P.; GITLIN, H.M. Manufactoring variations and drip irrigation uniformity. Transactions of the $A S A E$, St. Joseph, 24(1): 113-9, $1981 \mathrm{~b}$. 
BRALTS, V.F.; WU, I.P.; GITLIN, H.M. Emitter plugging and drip irrigation lateral I ine hydraulics. Transactions of the ASAE, St. Joseph, 25(5): 1274-81, 1982.

CHRISTIANSEN, J.E. Irrigation by sprinkling. Berkeley, University of California Agricultural Experiment Station, 1942. 124p. CBulletin,670s.

CLEMMENS, A.J. A statistical analysis of trickle irrigation uniformity. Transactions of the ASAE, St. Joseph, 30(1): $169-75,1987$.

CUENCA, R. H. Irrigation system design; an engineering approach. Englewood Cliffs, Prentice Hall, 1989. 552p.

HART, W.E. \& REYNOLDS, W.N. Analytical design of sprinkler systems. Transactions of the ASAE, St. Joseph, 8(1): $83-5,89,1985$.

HOWELL, T. A. ; STEVENSON, D.S. ; ALJIBURY, F.K.; GITLIN, H.M.; WU, I.P. ; WARRICK, A.W. ; RAATS, P.A.C. Design and operation of trickle (drip) systems. In: JENSEN, M.E., ed. Design and operation of farm irrigation systems. St. Joseph, ASAE, 1983 . cap. 16, p.663-720.

JAMES, L. G. Principles of farm irrigation system design. New York, John Wiley, 1988. 543p.

KELLER, J. \& KARMELI, D. Trickle irrigation design parameters. Transactions of the ASAE, St. Joseph, 17(4):678-84, 1974.

MERRIAN, J.L. \& KELLER, J. Farm irrigation system evaluation; a guide for management. Logan, Utah State University, 1978. 285p.

MERRIAN, J.L.; SHEARER, M.N.; BURT, C. M. Evaluating irrigation systems and practices. In: JENSEN, M. E. ed. Desion and operation of farm irrigation systems. St. Joseph. ASAE, 1983 . cap. 17, p. $721-60$.

NAKAYAMA, F.S. \& BUCKS, D.A. Emmitter clogging effects on trickle irrigation uniformity. Transactions of the $A S A E$, St. Joseph, 24(1): 77-80, 1981.

NAKAYAMA, F.S.; BUCKS, D. A. ; CLEMMENS, A.J. Assessing trickle emitter application uniformity. Transactions of the $A S A E$, St. Joseph, 22( 4): 816-21, 1979.

NUEVO, F.A.S. Modelo computacional para dimensionamento da rede hidráulica em sistemas de irrigação localizada. Săo Carlos, 1992. 139p. CMestrado - Escola de Engenharia de São Carlos/USPJ. 
PIZARRO. F. Riegos localizados de alta frecuencia. Madrid, Artes Graficas Palermo, 1986. 460p.

SAMMIS, T.W. \& WU, I.P. Effect of drip irrigation design and management on crop yield. Transactions of the ASAE. St. Joseph, 28( 3 ): 832-8, 1985.

SOLOMON, $K$. Manufactoring variation of trickle emitters. Transactions of the ASAE. St. Joseph, 22(5): 1034-8, 1979.

SOLOMON, K. Global uniformity of trickle irrigation systems. Transactions of the ASAE, St. Joseph, 28(4): $1151-6,1985$.

SOLOMON, K. \& KELLER, J. Trickle irrigation uniformity and efficiency. Journal of Irrigation Drainage Division American Society of Civil Engineers, New York, 104(IR3): $293-306,1978$.

VERMEIREN, L. \& JOBLING, G. A. Localized irrigation. Roma, FAO, 1984. 203p. (FAO exIrrigation and Drainage Paper, 36).

WILCOX, J.C. \& SWAILES, G.E. Uniformity of water distribution by some undertree orchard sprinklers. Scientific Agricultural, Ottawa, 27(11): 565-83, 1947.

WU, I.P. \& GITLIN, H.M. Drip irrigation design based on uniformity. Transactions of the ASAE, St. Joseph, 17(3): $429-32,1974$. 